\title{
Sustainable solutions by integrating process synthesis-intensification
}

\author{
Garg, Nipun; Woodley, John M.; Gani, Rafiqul; Kontogeorgis, Georgios M.
}

\section{Published in:}

Computers \& Chemical Engineering

Link to article, DOI:

10.1016/j.compchemeng.2019.04.030

Publication date:

2019

Document Version

Peer reviewed version

Link back to DTU Orbit

\section{Citation (APA):}

Garg, N., Woodley, J. M., Gani, R., \& Kontogeorgis, G. M. (2019). Sustainable solutions by integrating process synthesis-intensification. Computers \& Chemical Engineering, 126, 499-519.

https://doi.org/10.1016/j.compchemeng.2019.04.030

\section{General rights}

Copyright and moral rights for the publications made accessible in the public portal are retained by the authors and/or other copyright owners and it is a condition of accessing publications that users recognise and abide by the legal requirements associated with these rights.

- Users may download and print one copy of any publication from the public portal for the purpose of private study or research.

- You may not further distribute the material or use it for any profit-making activity or commercial gain

- You may freely distribute the URL identifying the publication in the public portal 


\title{
Sustainable solutions by integrating process synthesis-intensification
}

\author{
Nipun Garg ${ }^{\mathrm{a}}$, John M. Woodley ${ }^{\mathrm{a}}$, Rafiqul Gani ${ }^{\mathrm{b}}$, Georgios M. Kontogeorgis ${ }^{\mathrm{a}^{*}}$ \\ ${ }^{a}$ Department of Chemical and Biochemical Engineering, Technical University of Denmark, Sфltofts \\ Plads, DK-2800 Kgs. Lyngby, Denmark \\ ${ }^{b}$ PSE for SPEED, Skyttemosen 6, DK-3450 Allerod, Denmark
}

*Corresponding author: Georgios M. Kontogeorgis, Ph. +45 452528 59, email: gk@kt.dtu.dk,

Keywords: Process Synthesis; Process Intensification; Phenomena-based methodology; Systematic framework; Sustainable solutions

\begin{abstract}
A practical way to generate sustainable design alternatives, counter ongoing challenges and future problems is to develop methods that are generic in nature and can be applied over a wide search space to determine innovative and hybrid/intensified unit operations (unit-ops). In this research, a systematic framework based on a 3-stage approach for sustainable process design is presented and its application to generate intensified and more sustainable alternatives highlighted. Within this framework, the phenomena-based synthesis methodology is extended in terms of a wider range of applications and ability to determine more feasible solutions. The framework with the extended methodology is capable of generating innovative solutions involving solid-liquid and liquid-liquid systems in addition to vapor-liquid and membrane systems that could be generated previously. Further, the phenomena database is expanded so that with the new list of phenomena and basic structures, new and intensified unit operations (membrane crystallization, membrane bio-reactor to name a few) are generated. The applicability of step by step method available through the framework is demonstrated through a case study involving the production of bio-succinic acid. In this case study, a novel superstructure network of alternatives is generated, from which an optimal processing route is identified. This processing route is then designed and analysed to identify process bottlenecks, based on which a set of targets for improvement are defined. Then, by applying an extended phenomena-based synthesis methodology; non-trade off, more sustainable and intensified solutions to produce bio-succinic acid are generated and verified through rigorous processes simulation.
\end{abstract}

\section{Introduction}

The journey to attain sustainable production in chemical and related industries is still in its early stages and there is a continuously rising expectation for improvement and innovation in the coming 
years (Välimäki, 2018). These chemical and biochemical processes produce products that are essential in daily life and become more and more important in meeting requirements of today's modern world. Simultaneously, they are also exerting negative impacts on the ecosystem. These impacts are generated because of many factors like excessive and inefficient use of natural resources, waste discharge into environment, ecological effect of the products, inefficient methods of production to name a few. These industrial processes span the chemical, petroleum, pharmaceutical, food, textile, electronic and bio-industry. For all these industries, along with economic benefits, maintaining sustainability, i.e., conserving resources, preventing waste generation and increasing productivity have also become a top priority. Thus, there is an increased interest in generating more sustainable and innovative processes that are also economically beneficial.

Process Intensification (PI) is one of the many ways that aims to drastically improve the process performance and bring improvements both in terms of sustainability and economics. It has emerged to be an important tool providing opportunities and solutions for the challenges mentioned and meet the requirements for more efficient and sustainable processes. One of the best-known, commercial applications of PI is the methyl acetate production process using reactive distillation by Eastman chemical company (Agreda et al., 1990). Here, five processing steps are integrated to achieve $80 \%$ reduction in energy and a large reduction in capital cost. Other successful developments of PI are membrane reactor (Gallucci et al., 2008), static mixers (Kim et al., 2017), membrane distillation (Calabro et al., 1994), heat exchanger reactor (Anxionnaz et al., 2008), reverse flow reactor (Smith and Mackley, 2006) etc. Also in bio-processes, PI principles are applied, for example, in fermentation operations. Opportunities like application of cell retention and insitu removal of products can significantly improve fermentation processes. The main challenge here for PI is to have reasonably accurate estimates to find the optimal balance between transport, mixing and kinetics - improving the performance of fermentation processes (Noorman et al., 2018). Besides, there are PI technologies that are developed at a lab scale, but have not yet found application at industrial level (for example technologies using external energy sources like microwave, ultrasound, centrifugal and electric fields). Some of the challenges that restrict the deployment of developed intensified technologies include the risk of failure, scale-up unknowns, unreliability of equipment performance, and uncertain safety, health, and environmental impacts (Quadrennial Technology Review, 2015). Tian et al. (2018) mentions in an extensive review that, "PI is often considered as a toolbox having certain examples for process improvement rather than a powerful, systematic and strategic approach for innovation". Thus, the full potential of PI is yet to be explored in generating systematic, more sustainable, innovative and efficient solutions. 
Process Intensification can be performed using different approaches that are categorized as heuristic, mathematical programming and hybrid approaches. Heuristic approaches are based on information or rules which are built over time from experiences, different problem insights, engineering data and thumb rules. Several heuristics-based process intensification methods are developed where research from Bessling et al. (1997) and Kiss et al. (2007) focuses on intensification of a particular section of a process while work from Siirola, (1996) and Portha et al. (2014) intensify the entire process. Mathematical programming approaches determine the optimal solution through superstructure based optimization techniques. Mathematical programming approaches are proposed by Caballero and Grossmann, (2004), Ramapriya et al. (2014), Chen and Grossmann, (2017) where a section of process is intensified, while, methods from Papalexandri and Pistikopoulos, (1996), da Cruz et al. (2017), Li et al. (2017) and Demirel et al. (2017) perform intensification of the entire process or a part of the process at different scales. Hybrid approaches aim at combining the advantages of both heuristic and mathematical programming approaches. These generally concentrate on narrowing down the search space to reduce the size of the problem by removing redundant alternatives. Examples of hybrid approaches are Freund and Sundmacher, (2008), Peschel et al. (2012) and Seifert et al. (2012) intensifying a section of process while Lutze et al. (2013), Babi et al. (2015) and Tula et al. (2017) have reported multiscale methods to intensify the whole or a part of the process.

In terms of classification, PI can be achieved at various scales across different domains. According to Babi et al. (2015), PI can be performed at different scales, i.e., unit operation, task and phenomena scale. At unit operation scale, individual unit operations that constitute the process are considered for intensification. Further at the task scale, the functions performed by a specific unit operation are considered. A task can be defined as a purpose that it fulfils in the process such as reaction, separation, mixing or energy supply. Examples of PI performed at unit operation and task scales are dividing wall column, membrane reactor and reactive distillation (Demirel et al., 2017; Asprion and Kaibel, 2010; Halvorsen and Skogestad, 2011; Inoue et al., 2007; Holtbruegge et al., 2014). At phenomena scale, different phenomena affecting the driving force to perform a task are identified and further combined to generate innovative and intensified alternatives. Some of the examples of PI methodologies that operates at phenomena scale are Papalexandri and Pistikopoulos, (1996), Arizmendi-Sánchez and Sharratt, (2008), Rong et al. (2008), Lutze et al. (2013), Babi et al. (2015). According to Van Gerven and Stankiewicz, (2009), these improvements or enhancements can be achieved across four different domains that are process structure, energy, synergy and time. Time domain involves improvement of the kinetics, reduction of time, i.e., maximization of the speed and effectiveness of the events at different scales. Space domains consider maximization of homogeneity, 
for example creation of identical conditions for each molecule within the considered system. Energy (or thermodynamics) domain includes relaxation of transport limitations thus maximizing the driving forces and various transfer areas. Synergy domain aims to maximize the integration of different tasks for example, reaction combined with heat exchanger or alternative energy source like microwave to improve overall performance.

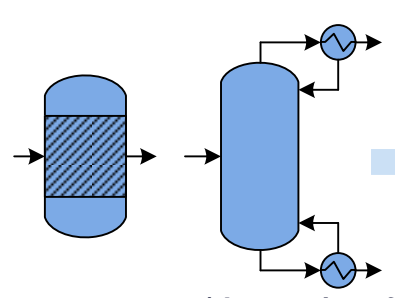

a) Integration of Unit Operations

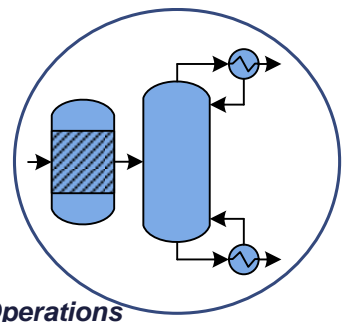

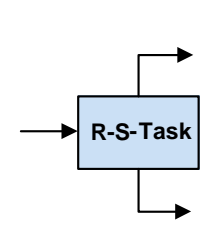

b) Integration of Tasks
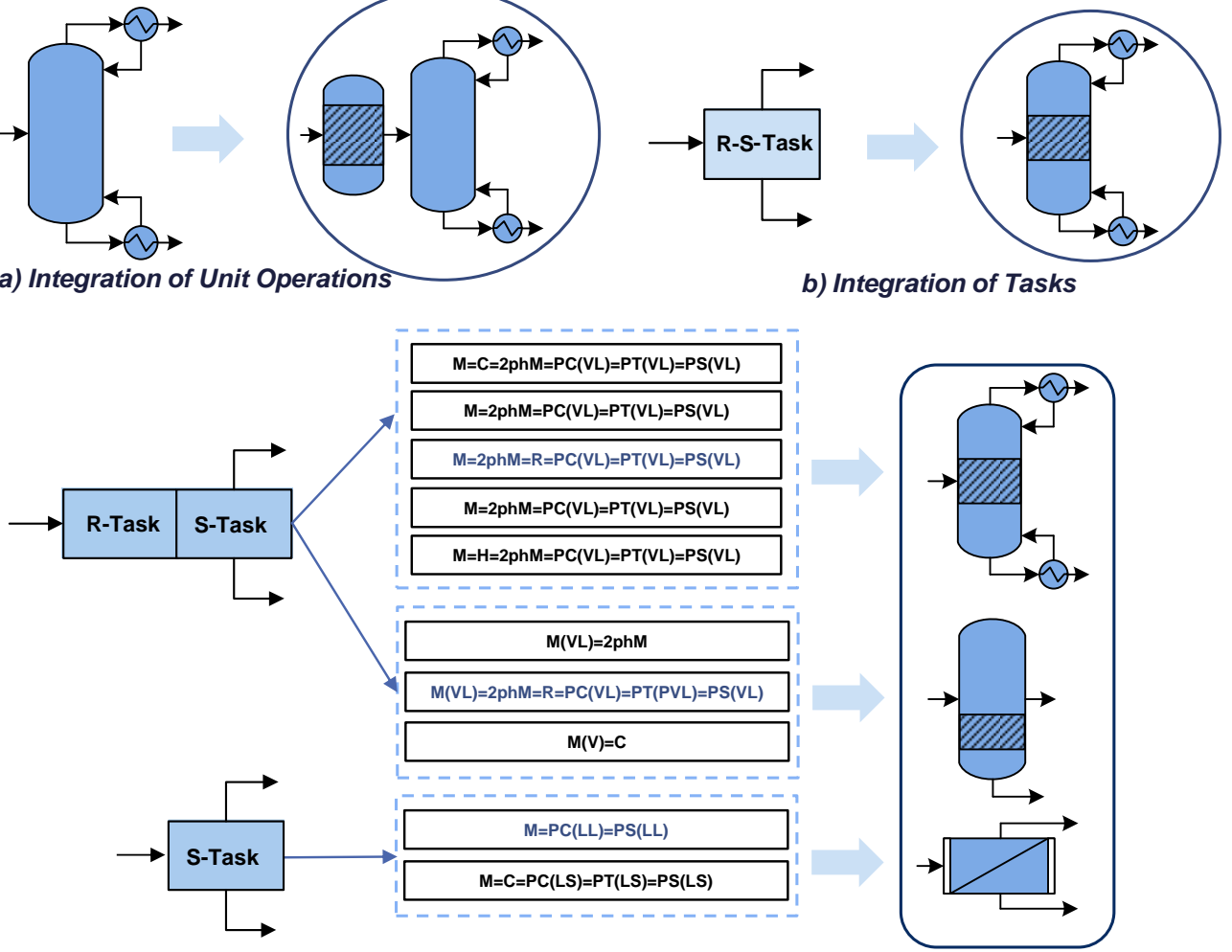

c) Integration and/or enhancement of phenomena

Figure 1: Different ways to perform PI ( $R$ and $S$ denotes reaction and separation)

Process synthesis aims to find the best processing route among numerous alternatives. However, it is generally limited to existing unit operations and thus, intensified/hybrid solutions are not included. On the other hand, PI aims to improve the processes and their efficiency. So, by integrating process synthesis and PI in early stages of design, the current search space of unit operations can be increased to generate more sustainable, new and innovative solutions. Process intensification can be performed (Lutze et al., 2010) by a) integration of unit operations, b) integration of tasks and c) integration or enhancement of phenomena (see section 2 for phenomena based synthesis-intensification) involved within the process (figure 1). As shown in figures $1 \mathrm{a}$ and $1 \mathrm{~b}$, there are not many alternatives when intensification is performed at unit operation or task levels. However, as shown in figure 1c, the same task (left hand side of Fig 1c) can lead to new intensified equipment such as reactive distillation, 
membrane-based reactor-separator (right hand side of Fig 1c) through different combinations of phenomena (middle of Fig 1c). Note that in Fig 1c, only a few combinations of the phenomena are highlighted.

Sustainable process synthesis-intensification is defined as the generation of more sustainable process alternatives that correspond to improved values of a set of targeted performance parameters obtained by integration of unit operations, integration of functions and phenomena's or targeted enhancement of the phenomena for a set of target operations (adopted from Lutze et al., 2013 and Babi et al., 2015). A systematic multi-stage and multi-scale approach to carry out sustainable process synthesis intensification is developed by Babi et al. (2015). It consists of three stages: Synthesis, Design (\& Analysis) and Innovation. An overview of the 3-stage approach along with objective of each stage is shown in figure 2.

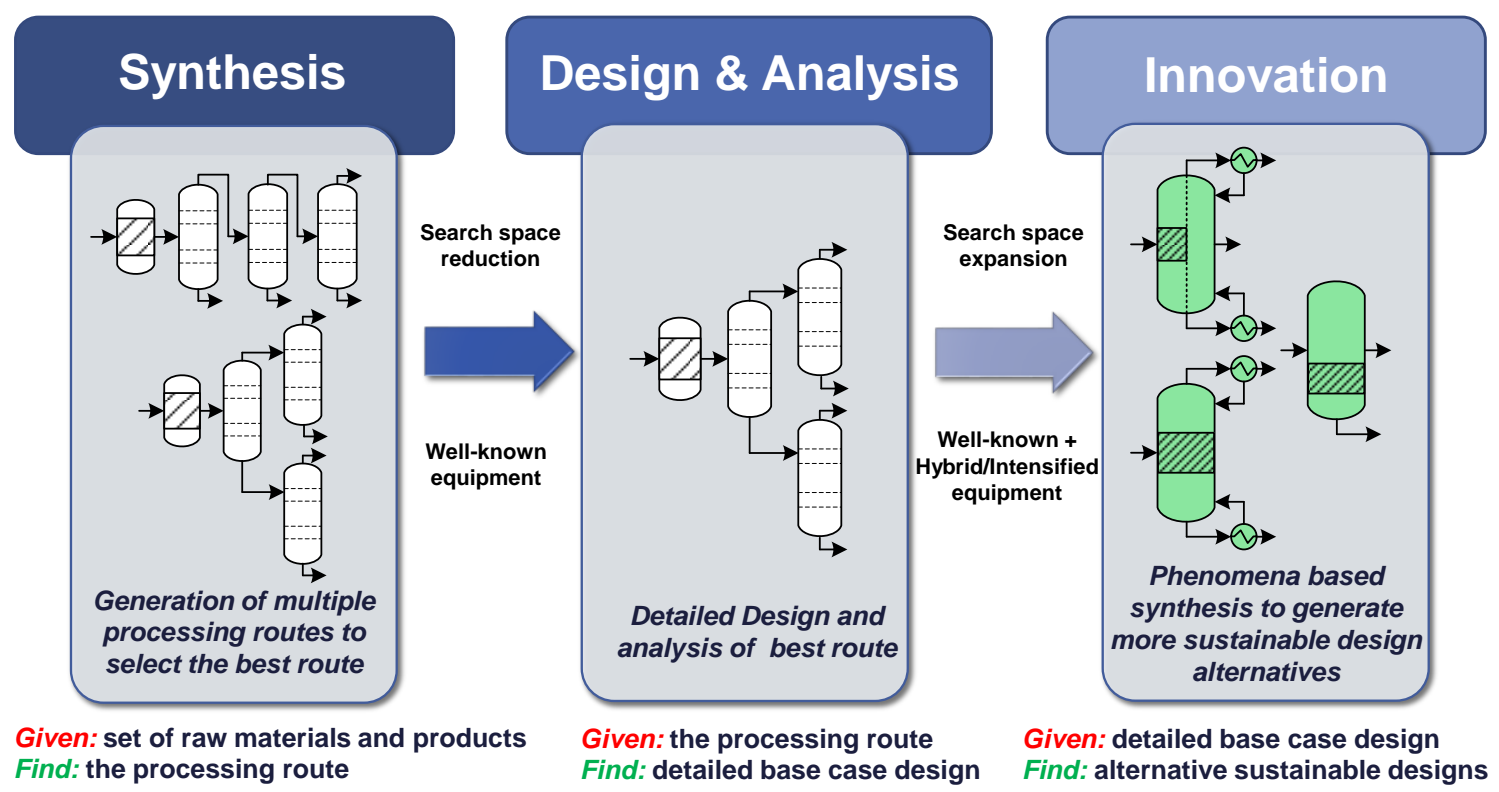

Figure 2: An overview of the 3-stage approach to sustainable process design

In Stage 1, i.e., synthesis stage, an optimal processing route (base case) to convert a set of raw materials into desired products is identified from numerous feasible alternatives, subject to process constraints and predefined performance criteria. This can be done by either directly doing literature survey or by application of approaches like decomposition-based approach (Tula et al., 2017), thermodynamic based insights (Jaksland et al., 1995) or superstructure based optimization approach (Grossmann, 2012; Bertran et al., 2017). In stage 2, the optimal processing route (flowsheet) identified in stage 1 , is designed in detail to establish the base case design and then analyze in terms of economics, sustainability and life cycle assessment. Based on this analysis, process hot-spots are 
identified which are translated to design targets. In stage 3, a phenomena-based synthesisintensification methodology is applied to generate feasible flowsheet alternatives. The final designs are then verified and compared with the base case through a set of pre-defined performance criteria to determine non-trade off, intensified and more sustainable process alternatives.

The three stages can also be performed independently, depending on available input information. For example, if a process flowsheet already exists, stage 2 can be performed directly. As shown in figure 2, a key point of this approach is that the search space of unit operations is not limited to existing and well-known equipment. Moving from stage 1 to 2, the search space is reduced as the number of alternatives reduces to one optimal process flowsheet based on set objectives. Furthermore, from stage 2 to stage 3, the search space is expanded in such a way that hybrid and intensified unit operations are also included along with existing solutions.

In this paper, the detailed workflow available within the extended framework together with the main actions needed for successful application of each step is presented. The framework is applied to a case study of industrial importance that is the production of bio-succinic acid, where important features of the method are highlighted. In its application, the superstructure-based optimization is performed for various scenarios to consider the influence of different parameters on the optimization, for example by varying the objective function, varying the prices of material and utilities according to different locations. The selected alternative is further developed in the design and innovation stages of the framework to identify more sustainable and intensified designs.

\section{Phenomena based synthesis-intensification - Definitions and concept}

Phenomena based synthesis is defined as the generation of process alternatives from the combination of phenomena building blocks (PBBs) at the lowest scale (phenomena) that perform a task at the higher scale (unit operation) (Babi et al., 2015). Phenomena based synthesis is a rule-based approach and is analogous to Computer Aided Molecular Design (CAMD) (Harper and Gani, 2000). In CAMD, different set of atoms are combined to generate functional groups that are further combined to generate molecules with desired set of properties. Similarly, in phenomena-based synthesis, the unit operations (analogous to molecules) are transformed into task or set of tasks (analogous to groups) performed by them, that are further decomposed into set of phenomena called PBB's i.e. phenomena building blocks (analogous to atoms). Then these selected phenomena are combined using combination rules to generate simultaneous phenomena building blocks (SPB's) (analogous to groups), which are combined to generate structures that perform a task or set of tasks further translated to unit operations (analogous to new feasible molecules). Similar to set of desired properties in 
CAMD, the alternatives generated should satisfy predefined performance criteria. Figure 3 highlights the basic concepts behind PBB's, SPB's and basic structures and how these can be combined to generate new and innovative solutions.

\subsection{Phenomena building block (PBB) and simultaneous phenomena building block (SPB)}

A phenomena or a phenomena building block (PBB) is defined as a smallest unit at the lowest level of aggregation that can, individually or in combination, perform a task or a part of a task in a chemical or a biochemical process (adapted from Babi et al., 2015).

A chemical or biochemical process can be represented by combinations of different phenomena occurring within the process in terms of mass, energy and momentum transfer. Lutze et al. (2013), defines a list of such phenomena or PBB's to represent different processes. These 9 PBB's are mixing (M), two-phase mixing (2phM), heating $(\mathrm{H})$, cooling $(\mathrm{C})$, reaction $(\mathrm{R})$, phase contact $(\mathrm{PC})$, phase transition (PT), phase separation (PS) and dividing (D). The inlet/outlet stream conditions while defining PBB's can be any of the following: liquid (L), vapor and liquid (VL), liquid-liquid (LL) vapor (V), vapor-liquid-liquid (VLL), solid (S) and solid-liquid (SL). Here, each PBB contributes to mass and energy balance for a specific system boundary.

A simultaneous phenomena building block (SPB) is defined as the combination of one of more PBB's using predefined combination rules that can perform a task or part of task in a chemical or biochemical process (adapted from Babi et al., 2015). Figure 3, shows the example of a reactor for a liquid phase exothermic reaction. It can be described in terms of phenomena as $M(L)$ i.e. mixing of the liquid components in the reaction $\mathrm{R}(\mathrm{L})$ where ' $\mathrm{L}$ ' represents the reaction phase and $\mathrm{C}$ is cooling required to remove the heat generated as the reaction is exothermic. Thus, using these PBB simultaneously in combination for a reaction task becomes a simultaneous phenomenon building block (SPB).

\subsection{Basic structures}

A basic structure is defined based on a SPB or a combination of multiple SPB's using predefined combination rules based on thermodynamic insights (Jaksland et al., 1995), that can perform a targeted or a set of targeted tasks in a chemical or biochemical process (adopted from Babi et al., 2015). Considering the same reaction task as in figure 3, we see that three different PBB's combine to make a SPB that performs the whole reaction task. Thus, in this case a single SPB is a basic structure. Now, considering an example of distillation column (separation task) in figure 3, a set of PBB's are combined to form 3 different SPB's. These SPB's are combined in order to make a basic structure which is translated to perform a separation task. 

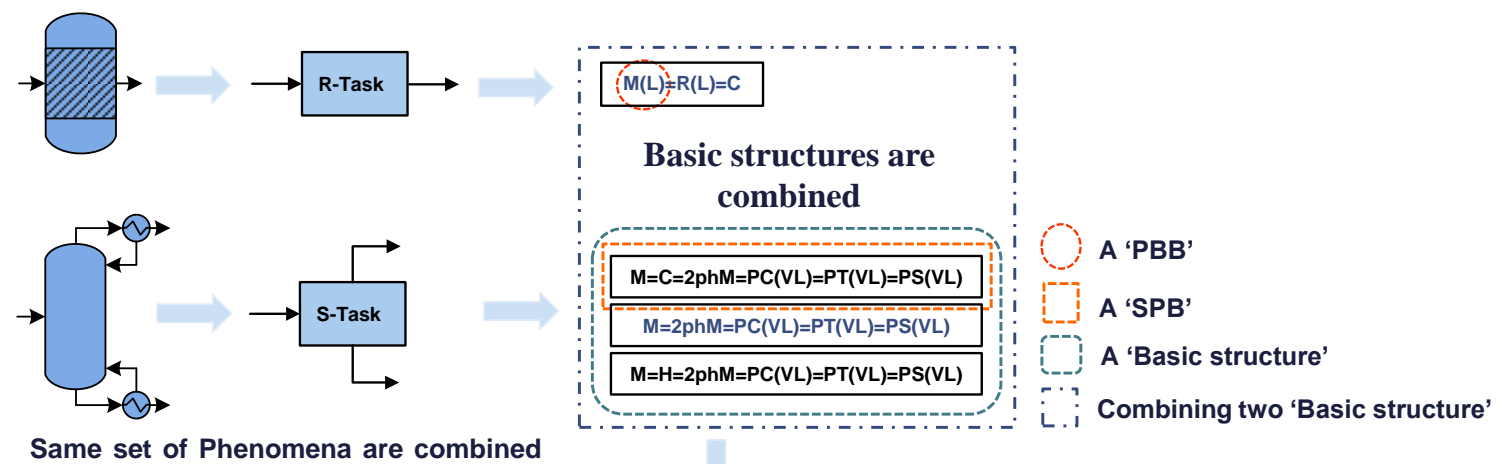

Same set of Phenomena are combined to generate new feasible solutions
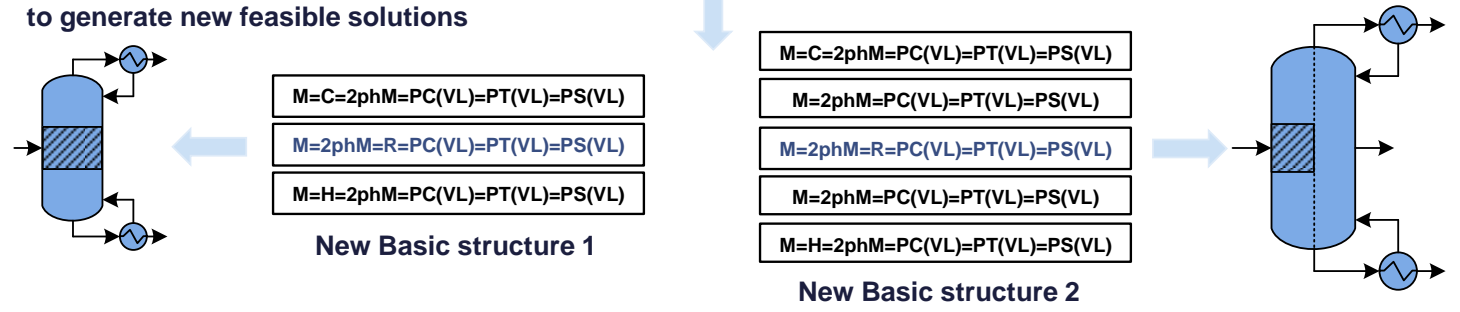

Figure 3: An overview of concept behind phenomena-based synthesis

\section{Sustainable process synthesis-intensification framework}

The sustainable process synthesis-intensification framework (figure 4) is based on 3-stage approach developed by Babi et al. (2015). The framework hosts an extended list of databases translating unit operation to phenomena, extended algorithms to include solid-liquid systems and new combination rules to generate basic structures translating to new and innovative solutions. The methodology implemented in the framework consists of 8 steps across 3 stages. After an objective of the problem is defined, the following systematic steps are followed to generate more sustainable and innovative process alternatives.

\subsection{Stage 1: Synthesis}

Objective: To identify an optimal processing route for the desired product(s) among numerous process alternatives.

3.1.1. Step 1 Synthesis problem definition - The first step within the synthesis stage is to define the general synthesis problem. It includes gathering information about desired product(s) for example purity, grade, capacity and cost along with the major objective of the synthesis stage. In this step other general information regarding major producers, raw materials, reaction, conversion is also collected. The information can be gathered by performing literature search or using available databases for example the ICAS database (Gani et al., 1997). 


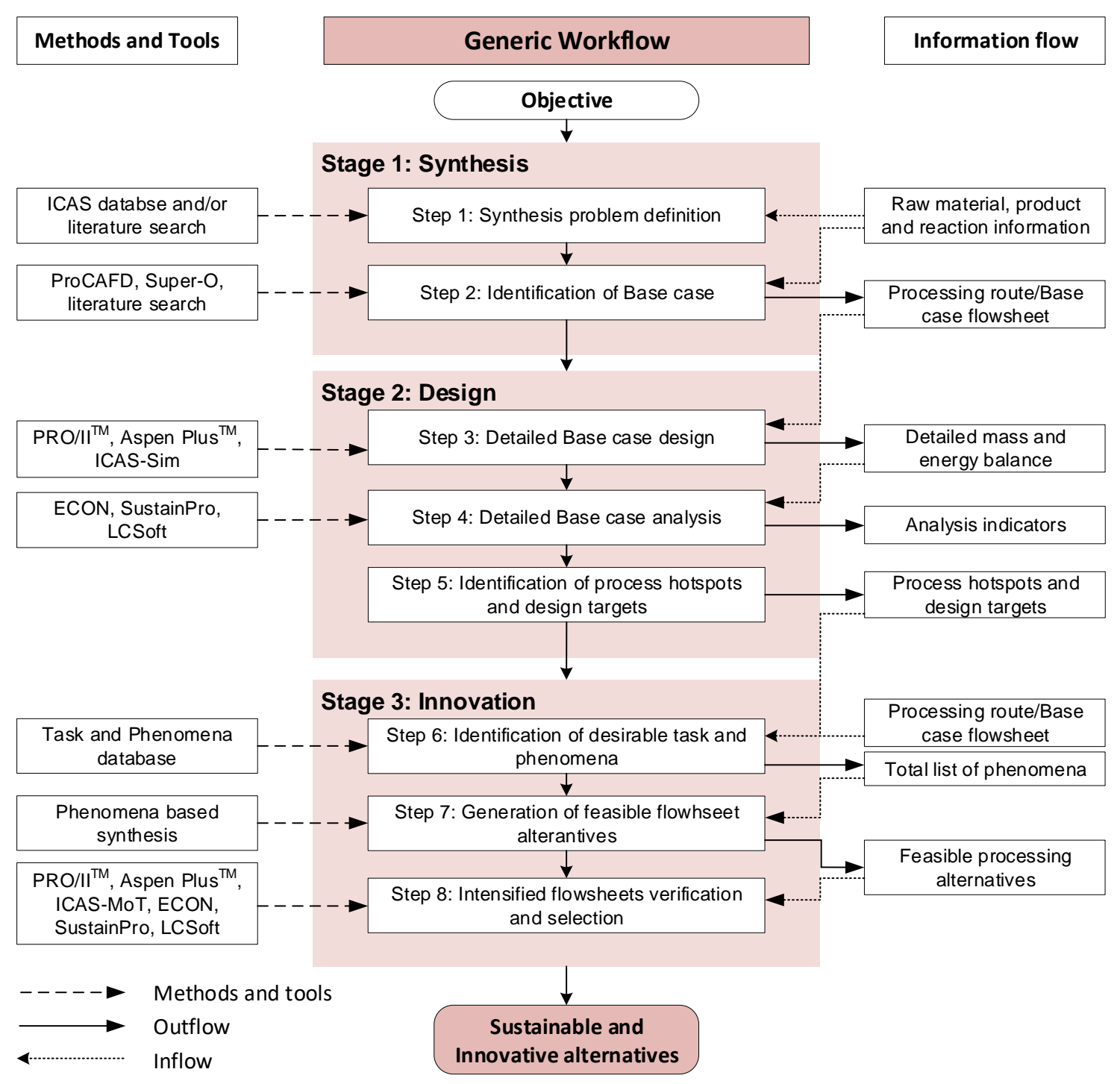

Figure 4: Systematic framework for sustainable process synthesis-intensification

3.1.2. Step 2 Identification of base case - In the second step, an optimal processing route (base case) is identified that converts selected set of raw materials into desired product(s). The base case can be either identified by performing literature survey or generated using different approaches. Example of some of many approaches are mathematical optimization of a superstructure network (Grossmann, 2012; Bertran et al., 2017), decomposition-based approach (Tula et al., 2017) or using thermodynamic insights (Jaksland et al., 1995). Software tools like Super-O (Bertran et al., 2017), ProCAFD (Tula et al., 2017) are used to quickly identify the optimal processing route. The base case flowsheet generated in this step generally does not include hybrid/intensified unit operations. 


\subsection{Stage 2: Design (\& analysis)}

Objective: To perform detailed design $\&$ analysis to identify process hotspots and set design targets.

3.2.1. Step 3 Detailed base case design - The rigorous simulation of the base case is performed in order to extract detailed mass and energy balance data. The basic information required for this step includes number of unit operations and streams in the process, reaction data, number of compounds and product recovery. Different software tools that can be used to perform simulation are PRO/II ${ }^{\mathrm{TM}}$, ICAS-Sim (Gani et al., 1997) or Aspen Plus ${ }^{\mathrm{TM}}$.

3.2.2. Step 4 Detailed base case analysis - The base case is analyzed in terms of economics, sustainability and environmental performance to identify process hot-spots. Economic analysis is performed to estimate the capital and utility costs associated with the process. Thus, the process hotspots in terms of unit operations that are having highest utility cost or capital expenses can be identified. Sustainability analysis is performed to identify critical flow paths (both open and closed) within the process. It is performed based on an indicator-based methodology (Carvalho et al., 2013). The main indicators estimated are material value added (MVA), energy and waste cost (EWC) and total value added (TVA). Life cycle assessment analysis is performed to identify the potential environmental impacts of the process. Some of the main environmental factors calculated are carbon footprint, HTPI ((Human Toxicity Potential by Ingestion), HTPE (Human Toxicity Potential by Exposure) and GWP (Global Warming Potential). Software tools that are used to carry out analysis are ECON (Kalakul et al., 2014), SustainPro (Carvalho et al., 2013) and LCSoft (Kalakul et al., 2014).

3.2.3. Step 5 Identification of process hotspots and design targets - Based on the indicator values, process hotspots are identified using the database of attributes associated with the base case property and possible cause of process hotspot. For example, the sustainability analysis identifies an open path with high negative value of MVA signifying raw material losses in the waste stream. This is because of the presence of unreacted raw materials in the reactor outlet which is further due to incomplete conversion caused by equilibrium limited reaction. Thus, the process hot-spots in this case would be activation problems, limiting equilibrium or limited heat/mass transfer in the reaction task. Further, using a database, identified hotspots are translated to design targets. For example, for the above identified hotspot, the possible design targets would be the increase in raw material conversion, change of catalyst, use of solvent in the reaction, identification of new reaction pathway, reduction of raw material loss, unit operations reduction, product 
purity, production target and waste minimization. These design targets are then set to be achieved in the innovation stage. A complete list of database to translate indicator values to process hotspots to design targets is available in Babi et al., 2015.

\subsection{Stage 3: Innovation}

Objective: To generate more sustainable and intensified/hybrid alternatives using phenomena-based synthesis method.

3.3.1. Step 6 Identification of desirable task and phenomena - The first action of this step is to translate the base case flowsheet into a task-based flowsheet (for example a reactor unit operation performs a reaction task, or a distillation column performs a separation task). The task-based flowsheet is further translated to phenomena-based flowsheet to identify an initial list of PBB's. A list of desirable tasks and additional list of PBB's is identified based on pure component $\&$ mixture property analysis and process hotspots identified in step 5. These phenomena are then added to the initial list of phenomena leading to an increased search space. Then an operating window i.e. a feasible range of operating variables is identified for each phenomena.

3.3.2. Step 7 Generation offeasible flowsheet alternatives -A list of feasible SPB's is identified from the total number of possible SPB's generated using pre-defined combination rules. Then, a task-based superstructure of alternatives is generated where feasibility of the identified tasks is checked. Further, based on the feasible SPB's, corresponding basic structures are identified that can perform identified task in superstructure. Then the taskbased flowsheets are identified from the basic structures or combination of basic structures which are translated to process flowsheet alternatives at the unit operation scale. The basic structures that are translated to unit operation includes both well-known and intensified options. This is because same basic structures can perform multiple tasks and thus can be combined to come up with an innovative unit operation. Similarly, multiple basic structures can perform same task, thereby expanding the search space of unit operations. If a feasible basic structure and its corresponding unit operation do not exist, then in principle, a new unit operation is generated.

3.3.3. Step 8 Intensified flowsheets verification and selection - In this step, the simulation or a model-based analysis for the generated flowsheet alternatives is performed to verify and analyze the performance of hybrid or intensified unit operations. This can be performed using suitable tools like ICAS-MoT (Heitzig et al., 2011). Then, an economic, 
sustainability and LCA analysis is performed for all the feasible alternatives to calculate the performance parameters. The improvements related to sustainability, economics and LCA factors are compared with the base case. For an intensified alternative to be a nontrade off solution i.e. more sustainable and economic, it must show improvements (or no change) with respect to all the selected performance criteria parameters.

Note: The phenomena-based synthesis method in innovation stage consist of different algorithms (Babi et al., 2015) that are extended in terms of application. A list of extended databases for algorithms used, with brief examples including new intensified equipment is given in the supplementary material. These algorithms are extended to solid-liquid, liquid-liquid phenomena from vapor-liquid (Babi et al., 2015) to be more generic, flexible in application and generate a wide range of innovative and intensified alternatives.

\section{Application of the framework: Production of Bio-Succinic Acid}

The systematic framework is applied step by step to generate more sustainable and intensified process alternatives for the production of bio-succinic acid. This case study has been selected because succinic acid, a four-carbon dicarboxylic acid is one of the most widely used platform chemical and is a precursor to produce different chemicals with application in food, pharma and various other chemical sectors (Song et al., 2006). Its demand is rising exponentially and is projected to reach 247.9 thousand ton (t) by 2021 (Technavio, 2018). Moreover, increasing interest in sustainability along with dynamic situation of petrochemical industry has created attraction towards production of bio-based chemicals such as succinic acid. Alongside this, the production of bio-succinic acid is favorable for reduction of carbon footprint since it uses $\mathrm{CO}_{2}$ as an additional carbon source. It also possesses great potential to replace chemicals like phthalic anhydride and adipic acid used in plasticizers and polyurethanes both very big scale bulk chemicals.

\section{Objective of the case study:}

The first task of the framework is to define main objective of the case study. It is as follows:

- To identify more sustainable and intensified process alternatives utilizing $\mathrm{CO}_{2}$ for production of bio-succinic acid.

\subsection{Stage 1 - Synthesis}

The objective of the synthesis stage is to identify the reference process flowsheet (base case). According to the framework, synthesis stage is performed in following two steps: 


\subsubsection{Step 1 - General problem definition}

The general synthesis problem for this case study is to find an optimal processing route among numerous alternatives for production of bio-succinic acid with a purity of at least 99 wt. \% (pharmaceutical grade). Additionally, basic information about succinic acid (product), its raw material(s), target production, basic reaction information for example conversion is also collected.

Some of the major producers of bio-succinic acid are Bio Amber Inc (joint venture of DNP Green Technology and ARD), Reverdia (joint venture of DSM and Roquette), Myriant Corporation and Succinity (joint venture of BASF and Corbion Purac) (Choi et al., 2015). The production plant owned by Bio Amber in Sarnia (Canada) has the highest capacity of 30 kilo ton per year (kt/y) (Cavani et al., 2016). Thus, the production target for this case study is set to produce $30 \mathrm{kt} / \mathrm{y}$ of succinic acid. Over the last 30 years, the production of bio-succinic acid has been the subject of interest to many researchers and industries (Mckinlay et al., 2007; Bechthold et al., 2008). Thus, there are diverse options proposed in literature in building a process for bio-succinic acid production. Traditionally, biochemical processes are designed around the best choice of host organism. But a process is called successful if it can be applied commercially with optimized capital and operating costs. This includes host micro-organism, biochemical pathway, fermentation conditions and downstream process. Two distinctive solutions based on the $\mathrm{pH}$ of the fermentation broth have been identified as most common across various research and patented articles (table 1). Fermentation using bacterial strains are conducted at neutral $\mathrm{pH}$ and are often capable of producing high yield. Though bacterial fermentation for succinic acid tend to have complex downstream process as it requires splitting of succinate salt to form succinic acid and an inorganic salt coproduct. Another solution focuses on acidophilic yeast fermentations that operate below the lower $\mathrm{pK}_{\mathrm{a}}$ value of succinic acid (4.2), that increases the ratio of succinic acid to succinate salts simplifying the downstream process but do not generally give substantial yield and productivity. Thus, both type of processes is considered for this case study.

Bio-based succinic acid has an attractive theoretical yield of $1.124 \mathrm{~g} / \mathrm{g}$ of glucose and $1.283 \mathrm{~g} / \mathrm{g}$ of glycerol, which is the highest among bio-based chemicals. This leads to an efficient use of feedstocks, less volatility and lower raw material costs. Thus, based on the attractive theoretical yield, along with Glucose and Glycerol, four different raw materials (Glucose, Glycerol, Maltose and Sucrose) are considered. As defined in objective, only those fermentations are considered that uses $\mathrm{CO}_{2}$ as the raw material. This is due to the following two reasons, it acts as an additional carbon source and secondly a sustainable solution to reduce carbon footprint. An example of abstract sustainable scheme for production of bio-succinic acid in presence of bacteria or yeast is shown in figure 5 . 


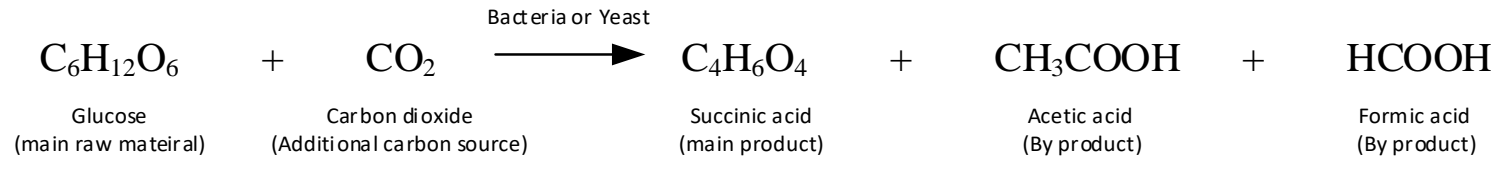

Figure 5: An example of abstract reaction scheme for bio-succinic acid

The production of bio-succinic acid can be carried out using different feedstocks and several microorganisms. A lot of research has been done to identify the best strains giving optimal yield, high concentration and high productivity. Some of the example of different micro-organisms used are Actinobacillus succinogenes (Guettler et al., 1999), Saccharomyces cerevisiae (Raab et al., 2010), Mannheimia succiniciproducens (Lee et al., 2002), Corynebacterium glutamicum (Okino et al., 2005; Litsanov et al., 2012), Yarrowia lipolytica (Yuzbashev et al., 2010), Anaerobiospirillum succiniciproducens (Lee et al., 2003), Bacteroides fragilis (Isar et al., 2007), Prevotella ruminicola and Ruminobacter amylophilus (Geuttler, Jain and Soni, 1998), Fibrobacter succinogenes (Li et al., 2010), Basfia succinoproducens (Scholten et al., 2009) and Escherichia coli (Donnelly et al., 1998; Sanchez et al., 2005, Jantama et al., 2008). A list of fermentation and related data based on the type of host micro-organism, raw material, yield, productivity and broth concentration is collected and is shown in table 1 . The data mentioned in table 1 is either directly taken from the mentioned references or is calculated based on the information given. Note that the list includes only those fermentations that utilizes $\mathrm{CO}_{2}$ as an additional carbon source.

\section{Table 1: Fermentation data to produce bio succinic acid using different strains}

(FERM-1: Datta, Glassner, Jain and Roy, (1992); FERM-2: Glassner and Datta, (1992); FERM-3: Rush and Fosmer, (2014); FERM-4: Van De Graaf, Vallianpoer, Fiey, Delattre and Schulten, (2012); FERM-5: Vemuri et al., 2002; FERM-6: Guettler, Jain and Rumler, (1996); FERM-7: Lee et al., 2008; FERM-8: \& FERM-9: Schroder, Haefner, Abendroth, Hollmann, Raddatz, Ernst and Gurski, (2014); FERM-10: S. Y. lee, J. W. Lee, Choi and Yi, (2014))

\begin{tabular}{ccccccccc}
\hline & Organism & Strain name & $\begin{array}{c}\text { Ferm } \\
\text { Type }\end{array}$ & $\begin{array}{c}\text { Carbon } \\
\text { source }\end{array}$ & $\begin{array}{c}\text { Titer } \\
(\mathbf{g} / \mathbf{l})\end{array}$ & $\begin{array}{c}\text { Yield } \\
(\mathbf{g} / \mathbf{g})\end{array}$ & $\begin{array}{c}\text { Productivity } \\
(\mathbf{g} / \mathbf{l} / \mathbf{h})\end{array}$ & $\begin{array}{c}\text { Broth } \\
\mathbf{p H}\end{array}$ \\
\hline FERM-1 & Bacteria & $\begin{array}{c}\text { A. } \\
\text { succinoproducens } \\
\text { ATCC 5348 }\end{array}$ & Batch & Glucose & 43.5 & 0.87 & 1.93 & 6.10 \\
FERM-2 & Bacteria & $\begin{array}{c}\text { A. } \\
\text { succinoproducens } \\
\text { ATCC 5348 }\end{array}$ & Batch & Glucose & 30.84 & 0.90 & 1.10 & 6.20 \\
FERM-3 & Yeast & $\begin{array}{c}\text { I. orientalis, } \\
13723\end{array}$ & Batch & Glucose & 48.2 & 0.45 & 0.97 & 3.00
\end{tabular}




\begin{tabular}{|c|c|c|c|c|c|c|c|c|}
\hline FERM-4 & Yeast & $\begin{array}{l}\text { S. cerevisiae, } \\
\text { SUC-297 }\end{array}$ & Fed-batch & Glucose & 43.0 & 0.31 & 0.45 & 3.00 \\
\hline FERM-5 & Bacteria & $\begin{array}{c}\text { E. coli, } \\
\text { AFP111/pTrc99A- } \\
\text { pyc }\end{array}$ & Fed-batch & Glucose & 99.2 & 1.10 & 1.30 & 6.80 \\
\hline FERM-6 & Bacteria & $\begin{array}{l}\text { A. succinogen, } \\
\text { FZ53 }\end{array}$ & Batch & Glucose & 105.8 & 0.83 & 1.36 & 6.08 \\
\hline FERM-7 & Bacteria & $\begin{array}{c}\text { M. } \\
\text { succiniciproducens } \\
\text { LPK7 }\end{array}$ & Fed-batch & Glucose & 52.43 & 0.76 & 1.80 & 6.50 \\
\hline FERM-8 & Bacteria & $\begin{array}{c}\text { B. } \\
\text { succiniciproducens } \\
\text { DD1 }\end{array}$ & Batch & Glycerol & 36.2 & 1.26 & 1.51 & 6.50 \\
\hline FERM-9 & Bacteria & $\begin{array}{c}\text { B. } \\
\text { succiniciproducens } \\
\text { LU } 15224\end{array}$ & Batch & $\begin{array}{l}\text { Glycerol } \\
+ \\
\text { Maltose }\end{array}$ & 69.8 & 1.11 & 2.91 & 6.50 \\
\hline FERM-10 & Bacteria & $\begin{array}{c}\text { M. } \\
\text { succiniciproducens } \\
\text { PALFK }\end{array}$ & Fed-batch & $\begin{array}{l}\text { Sucrose } \\
\quad+ \\
\text { Glycerol }\end{array}$ & 78.41 & 1.07 & 6.03 & 6.50 \\
\hline
\end{tabular}

\subsubsection{Step 2 -Identification of base case flowsheet}

As mentioned in the framework, numerous approaches can be applied to identify the optimal processing route. In this case study, the superstructure based mathematical optimization approach has been applied to meet the objective of synthesis stage. Superstructure based process synthesis is an effective way to determine the optimal pathway from a network of alternatives. This is because using a mathematical optimization approach for a superstructure, a large number of processing routes as possible alternatives in terms of processing steps and processing intervals can be generated. It is based on an integrated framework for synthesis and design of processing networks (Quaglia et al., 2013). The processing steps are defined as number of steps required to achieve the final result while processing intervals are defined as the alternatives within the processing step. This kind of superstructure representation has been termed as "Processing Step-Interval Network (PSIN)" (Bertran et al., 2017).

To generate a superstructure, the basic fermentation data is collected in step 1 (table 1). Further, there are different purification techniques or technologies available in literature to obtain succinic acid of a given purity. In principle, the minimum number of separation steps required to separate NC components is NC- minimum processing steps for a process is $\mathrm{NC}-1$ where NC is the number of steps. This is the minimum to separate all the compounds individually. But, in this case study the main objective is to produce pure succinic acid. Thus, the logical rules are also followed, for example 
after fermentation step, the biomass is removed first, and by-products present in low amount are not recovered.

Many of the various processing steps and intervals are thus identified based on available data and current technologies reported in the scientific literature (table 2). The economic data for product price, raw material costs, chemical costs and utility costs (Tan et al., 2017; Biorefinery database (Bertran et al., 2017); ICIS price reports, (2016); Ycharts, 2014; Costs of doing business in Thailand, (2014); Intratec utility pricing, (2016); Industrial Price Comparison - Rocky Mountain Power, (2018); Harrison, Todd P, Todd PW, Rudge, Petrides, (2015)) is given in supplementary material (section S1).

Table 2: Processing steps and processing intervals for superstructure

\begin{tabular}{|c|c|c|}
\hline & Processing Interval & Reference \\
\hline I. & Raw Material & \\
\hline GLU & Glucose & - \\
\hline GLY & Glycerol & - \\
\hline MAL & Maltose & - \\
\hline SUC & Sucrose & - \\
\hline II. & Fermentation & \\
\hline FERM 1 & Fermentation option 1 using bacterial strain and Glucose & US patent $5168055 \mathrm{~A}, 1992$ \\
\hline FERM 2 & Fermentation option 2 using bacterial strain and Glucose & US patent 5143834A, 1992 \\
\hline FERM 3 & Fermentation option 3 using yeast strain and Glucose & US patent $0363862 \mathrm{~A} 1,2014$ \\
\hline FERM 4 & Fermentation option 4 using yeast strain and Glucose & US patent $0238722 \mathrm{Al}, 2012$ \\
\hline FERM 5 & Fermentation option 5 using bacterial strain and Glucose & Vemuri et al., 2002 \\
\hline FERM 6 & Fermentation option 6 using bacterial strain and Glucose & US patent 5573931A, 1996 \\
\hline FERM 7 & Fermentation option 7 using bacterial strain and Glucose & Lee et al., 2008 \\
\hline FERM 8 & Fermentation option 8 using bacterial strain and Glycerol & US patent $8673598 \mathrm{~B} 2,2014$ \\
\hline FERM 9 & Fermentation option 9 using bacterial strain and Glycerol + Maltose & US patent $8673598 \mathrm{~B} 2,2014$ \\
\hline FERM 10 & Fermentation option 10 using bacterial strain and Sucrose + Glycerol & US patent $8691516 \mathrm{~B} 2,2014$ \\
\hline III. & Biomass Removal & \\
\hline BIOR-MFLT & Biomass removal using microfiltration & Vogel and Todaro, 1996; \\
\hline BIOR-ULFT & Biomass removal using ultrafiltration & WO patent $082050 \mathrm{~A} 1,2009$; \\
\hline BIOR-CENT & Biomass removal using centrifugation & WO patent $169447 \mathrm{~A} 1,2013$ \\
\hline
\end{tabular}




\begin{tabular}{|c|c|c|}
\hline IV. & Concentration Pre-Isolation & \\
\hline CPRI-DSTL & Concentrating the broth using distillation & WO patent $088239 \mathrm{~A} 2,2013$ \\
\hline CPRI-EVAP & Concentrating the broth using evaporation & US patent $0289742 \mathrm{~A} 1,2012$ \\
\hline CPRI-EXTR & Concentrating the broth using extraction & US patent 5412126A, 1993 \\
\hline CPRI-PVAP & Concentrating the broth using pervaporation & Baelen et al., 2005 \\
\hline BYPASS & Concentration pre-isolation step is bypassed & - \\
\hline V. & Isolation & \\
\hline SEP-CSSP & Isolation of succinic acid from succinate salt containing calcium & US patent $5168055 \mathrm{~A}, 1992$ \\
\hline SEP-IEXC & Isolation of succinic acid from succinate salt using ion-exchange & US patent $0289742 \mathrm{~A} 1,2012$ \\
\hline SEP-SUSP & Isolation of succinic acid from succinate salt using methanol & US patent $6265190 \mathrm{~B} 1,2001$ \\
\hline SEP-REXT & Isolation of succinic acid from succinate salt using reactive extraction & Vaswani, 2010 \\
\hline SEP-EDLS & Isolation of succinic acid from succinate salt using Electrodialysis & US patent 5143834A, 1992 \\
\hline BYPASS & Isolation step is bypassed & - \\
\hline VI. & Impurities Removal & \\
\hline IMPR-IEXC & Removal of soluble impurities using Ion exchange & US patent $8673598 \mathrm{~B} 2,2014$ \\
\hline IMPR-CTRT & Removal of soluble impurities using carbon treatment & Choi et al., 2016 \\
\hline IMPR-NFLT & Removal of soluble impurities using Nano-filtration & US patent $0289742 \mathrm{~A} 1,2012$ \\
\hline BYPASS & Impurities removal is bypassed & - \\
\hline VII. & Concentration Post-Isolation & \\
\hline CPSI-DSTL & Concentrating the broth using distillation & WO patent $088239 \mathrm{~A} 2,2013$ \\
\hline CPSI-EVAP & Concentrating the broth using evaporation & US patent $0289742 \mathrm{~A} 1,2012$ \\
\hline CPSI-EXTR & Concentrating the broth using extraction & US patent 5412126A, 1993 \\
\hline CPSI-PVAP & Concentrating the broth using pervaporation & Baelen et al., 2005 \\
\hline BYPASS & Concentration post-isolation step is bypassed & - \\
\hline VIII: & Purification & \\
\hline PUR-ECRY & Purification of succinic acid using evaporative crystallization & WO patent $064151 \mathrm{~A} 1,2011$ \\
\hline PUR-SCRY & Purification of succinic acid using solvent crystallization & US patent $6265190 \mathrm{~B} 1,2001$ \\
\hline PUR-CCRY & Purification of succinic acid using cooling crystallization & Choi et al., 2016 \\
\hline IX. & Drying & \\
\hline DRYING & Purification of succinic acid by removing remaining impurities & - \\
\hline $\mathbf{X}$. & Product & \\
\hline SUC ACD & Pharmaceutical grade succinic acid (>99 wt. \%) & - \\
\hline
\end{tabular}


The superstructure is set up in Super-O which is an interface to formulate and solve superstructurebased optimization problems (Bertran et al., 2017). The optimization problem is solved by using solvers from an external software GAMS (GAMS Development Corporation, 2012), where Super-O is a user interface to enter required data and information. Processing interval information on raw materials, main products, side products, reactions, chemical added, utilities and economic data such as product price, raw material cost and chemical cost has been collected from patents, published articles and scientific reports, available industrial data and databases. Every interval in the PSIN representation of the superstructure is modelled with the same set of generic equations representing a sequence of processing tasks, namely mixing, reaction, waste removal and product separation, as well as utility consumption. Multiple inlets to and outlets from the interval are allowed, including recycle streams from downstream intervals and bypasses. A representation of the generic model is shown in figure 6. Here, "f" represents the component flow rates at different positions for different parameters while "g" denotes the flow rate of added/removed component/utility. Further details regarding setting up the problem, generic mathematical model and entering the required data in SuperO can be read in detail in article by Bertran et al. (2017).

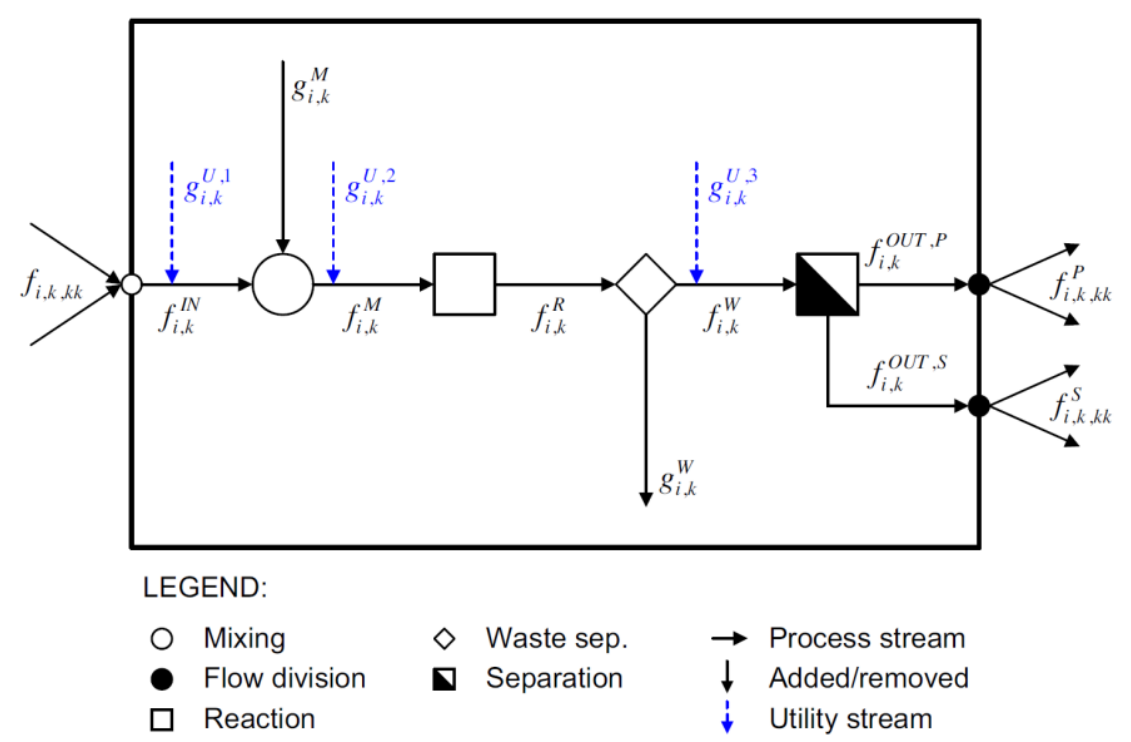

Figure 6: Generic processing interval scheme (Bertran et al., 2017)

The superstructure optimization is performed for 3 different scenarios based on location and objective function. Overall objective remains same for all the scenarios which is to maximize the profit. The 3 different scenarios are explained as follows:

- Scenario 1: The plant location is set to USA and the objective function is based upon sales of product 
- Scenario 2: The plant location is same as scenario 1 i.e. USA, but an additional effect of operating cost is added to the objective function

- Scenario 3: Same as scenario 2 except the plant location has been changed to Thailand

The superstructure describing the network of configurations for different processing routes has 8 processing steps and 33 processing intervals excluding raw material and product steps. The PSIN representation of alternatives containing the processing intervals, raw materials and products is shown in figure 7.

An optimization problem is solved for each scenario using the same generic model. The statistics of the optimization problem for bio succinic acid is shown in table 3 .

Table 3: Statistics for the optimization problem for bio succinic acid production

\begin{tabular}{lll}
\hline & No. of feed (NF) & 4 \\
Superstructure & No. of product (NP) & 1 \\
& No. of processing steps (NS) & 8 \\
& No. of intervals NI (excluding NF and NP) & 33 \\
\hline \multirow{3}{*}{ Model and Solver } & No. of equations (NEQ) & 989,003 \\
& No. of variables (NV) & 973,451 \\
& Problem type & 164 \\
& Solver & MILP \\
\hline
\end{tabular}

The results in terms of objective function for 3 different scenarios is shown in table 4 and optimal topology is shown in figure 7 denoted with different colors. It is observed that, the optimal topology for scenario 1 and 2 is coming out to be the same, while in scenario 3, the raw material and the fermentation has changed owing to one of the major reasons being lower prices of Glycerol as compared to the Glucose. The objective function depends on the product revenue; raw material, chemical and utility costs (scenario 2 and 3). Thus a sensitivity analysis on variation of prices is performed. From this analysis, $\pm 10 \%$ fluctuation in the product price brings \pm 14.3 to $\pm 18.3 \%$ change in the objective function for all the scenarios. Similarly, a $\pm 10 \%$ fluctuation in the raw material and utility prices brings \pm 1.3 to $\pm 3.2 \%$ and \pm 0.7 to $\pm 1.2 \%$ changes respectively, in the objective function for all the scenarios. In all the above cases, the optimal processing route (flowsheet) remains unchanged. The optimal processing route identified for different scenarios is as follows: 
- Scenario 1: GLU $\rightarrow$ FERM $5 \rightarrow$ BIOR-CENT $\rightarrow$ CPRI-DSTL $\rightarrow$ BYPASS $\rightarrow$ IMPR-CTRT $\rightarrow$ BYPASS $\rightarrow$ PUR-CCRY $\rightarrow$ DRYING $\rightarrow$ SUC ACD

- Scenario 2: GLU $\rightarrow$ FERM $5 \rightarrow$ BIOR-CENT $\rightarrow$ CPRI-DSTL $\rightarrow$ BYPASS $\rightarrow$ IMPR-CTRT $\rightarrow$ BYPASS $\rightarrow$ PUR-CCRY $\rightarrow$ DRYING $\rightarrow$ SUC ACD

- Scenario 3: GLY+MAL $\rightarrow$ FERM $9 \rightarrow$ BIOR-CENT $\rightarrow$ CPRI-DSTL $\rightarrow$ BYPASS $\rightarrow$ IMPR-CTRT $\rightarrow$ BYPASS $\rightarrow$ PUR-CCRY $\rightarrow$ DRYING $\rightarrow$ SUC ACD

Table 4: Results of the superstructure based mathematical optimization for 3 different scenarios

\begin{tabular}{llll}
\hline & Scenario 1 & Scenario 2 & Scenario 3 \\
\hline Location & USA & USA & Thailand \\
Objective function & $\mathrm{S}^{\mathrm{PROD}}-\mathrm{C}^{\mathrm{RAW}}-\mathrm{C}^{\mathrm{C}}$ & $\mathrm{S}^{\mathrm{PROD}}-\mathrm{C}^{\mathrm{RAW}}-\mathrm{C}^{\mathrm{C}}-\mathrm{C}^{\mathrm{U}}$ & $\mathrm{S}^{\mathrm{PROD}}-\mathrm{C}^{\mathrm{RAW}}-\mathrm{C}^{\mathrm{C}}-\mathrm{C}^{\mathrm{U}}$ \\
Total product sale $(\mathrm{M} \$ / \mathrm{y})$ & 70.02 & 70.02 & 70.02 \\
Raw material cost $(\mathrm{M} \$ \mathrm{y})$ & 12.19 & 12.19 & 6.44 \\
Chemicals cost $(\mathrm{M} \$ \mathrm{y})$ & 15.27 & 15.27 & 12.66 \\
Utilities cost $(\mathrm{M} \$ \mathrm{y})$ & - & 4.33 & 2.31 \\
Execution time $(\mathrm{seconds})$ & 2.50 & 2.52 & 2.56 \\
Objective function $(\mathrm{M} \$ / \mathrm{y})$ & 42.56 & 38.23 & 48.61 \\
\hline
\end{tabular}

The optimal processing routes identified for all 3 different scenarios are novel processing routes. Also, as shown in figure 7, along with optimal processing routes, 5 other existing routes in literature are also identified. These existing routes are denoted with different colors in the PSIN representation.

- Existing alternative 1 (Datta, Glassner, Jain and Roy, 1992): GLU $\rightarrow$ FERM $1 \rightarrow$ BIORMFLT $\rightarrow$ BYPASS $\rightarrow$ SEP-CSSP $\rightarrow$ BYPASS $\rightarrow$ CPSI-EVAP $\rightarrow$ PUR-ECRY $\rightarrow$ DRYING $\rightarrow$ SUC ACD

- Existing alternative 2 (Glassner and Datta, 1992): GLU $\rightarrow$ FERM $2 \rightarrow$ BIOR-MFLT $\rightarrow$ BYPASS $\rightarrow$ SEP-EDLS $\rightarrow$ BYPASS $\rightarrow$ BYPASS $\rightarrow$ PUR-CCRY $\rightarrow$ DRYING $\rightarrow$ SUC ACD

- Existing alternative 3 (Van De Graaf, Vallianpoer, Fiey, Delattre and Schulten, 2012): GLU $\rightarrow$ FERM $4 \rightarrow$ BIOR-MFLT $\rightarrow$ BYPASS $\rightarrow$ SEP-IEXC $\rightarrow$ BYPASS $\rightarrow$ CPSI-EVAP $\rightarrow$ PURECRY $\rightarrow$ DRYING $\rightarrow$ SUC ACD

- Existing alternative 4 (Vaswani, 2010): GLU $\rightarrow$ FERM $7 \rightarrow$ BIOR-UFLT $\rightarrow$ BYPASS $\rightarrow$ SEPREXT $\rightarrow$ BYPASS $\rightarrow$ CPSI-DSTL $\rightarrow$ PUR-CCRY $\rightarrow$ DRYING $\rightarrow$ SUC ACD 
- Existing alternative 5 (Schroder, Haefner, Abendroth, Hollmann, Raddatz, Ernst and Gurski, 2014): GLY+MAL $\rightarrow$ FERM $9 \rightarrow$ BIOR-MFLT $\rightarrow$ BYPASS $\rightarrow$ SEP-IEXC $\rightarrow$ BYPASS $\rightarrow$ CPSI-EVAP $\rightarrow$ PUR-CCRY $\rightarrow$ DRYING $\rightarrow$ SUC ACD

The optimal processing route from scenario 1 and 2 is considered for further analysis in stage 2 and 3. The process flowsheet for the selected alternative (base case flowsheet) is shown in figure 8 . The first step is fermentation where non-condensable gases are removed from the top of fermenter followed by centrifugation to separate the biomass from the culture broth. Then the cell free broth is distilled in order to concentrate the solution and facilitate crystallization. The color of the culture broth caused by certain impurities is removed by activated carbon treatment. Then the feed is sent to crystallizer where cooling crystallization is performed by lowering the $\mathrm{pH}$ followed by drying of the pure succinic acid crystals to remove any remaining water or impurities. 


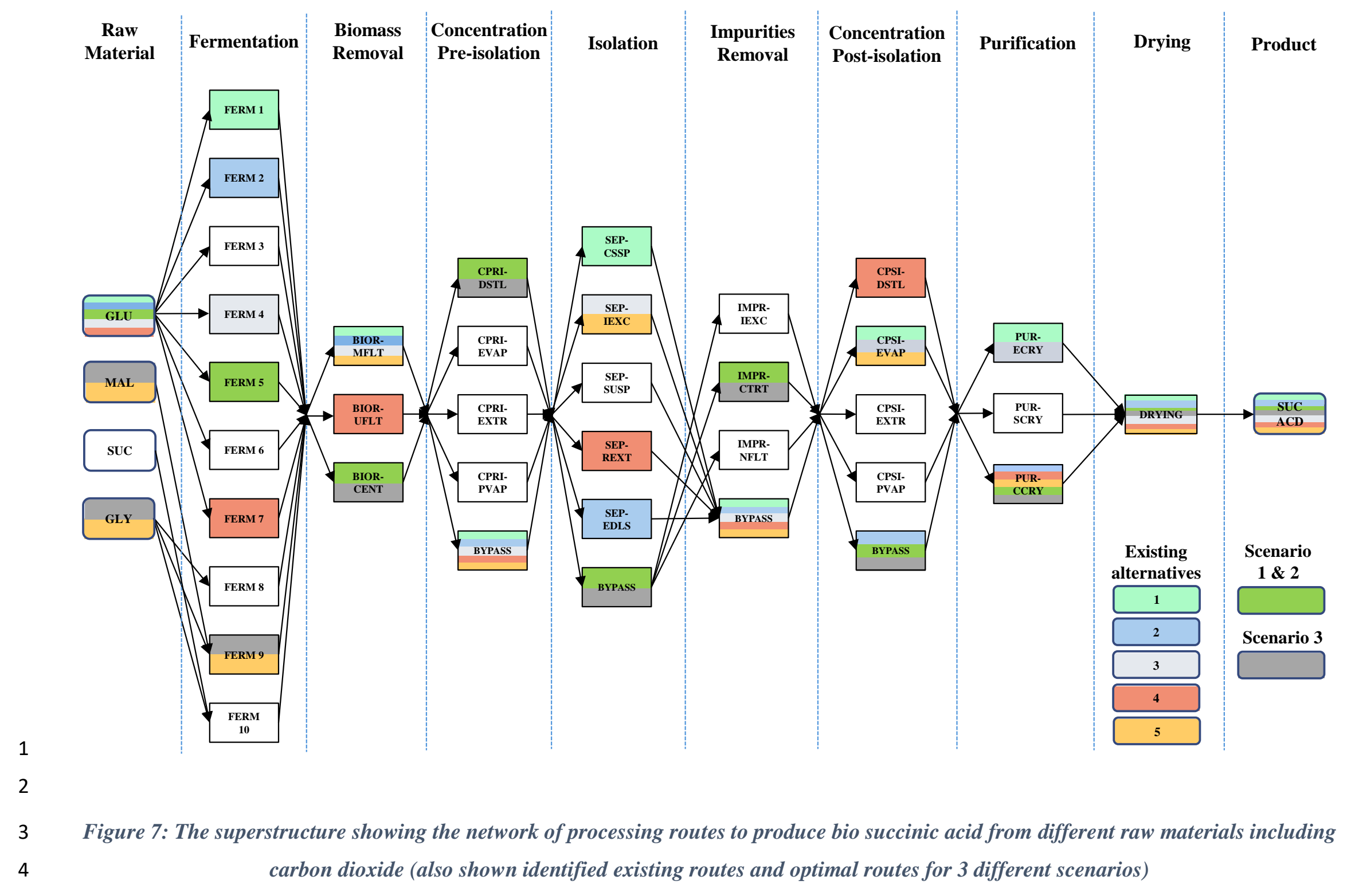


6 The objective of stage 2 is to perform detailed base case design, analyze the process, identify process

7 hotspots and set design targets for improvement to be achieved in innovation stage.
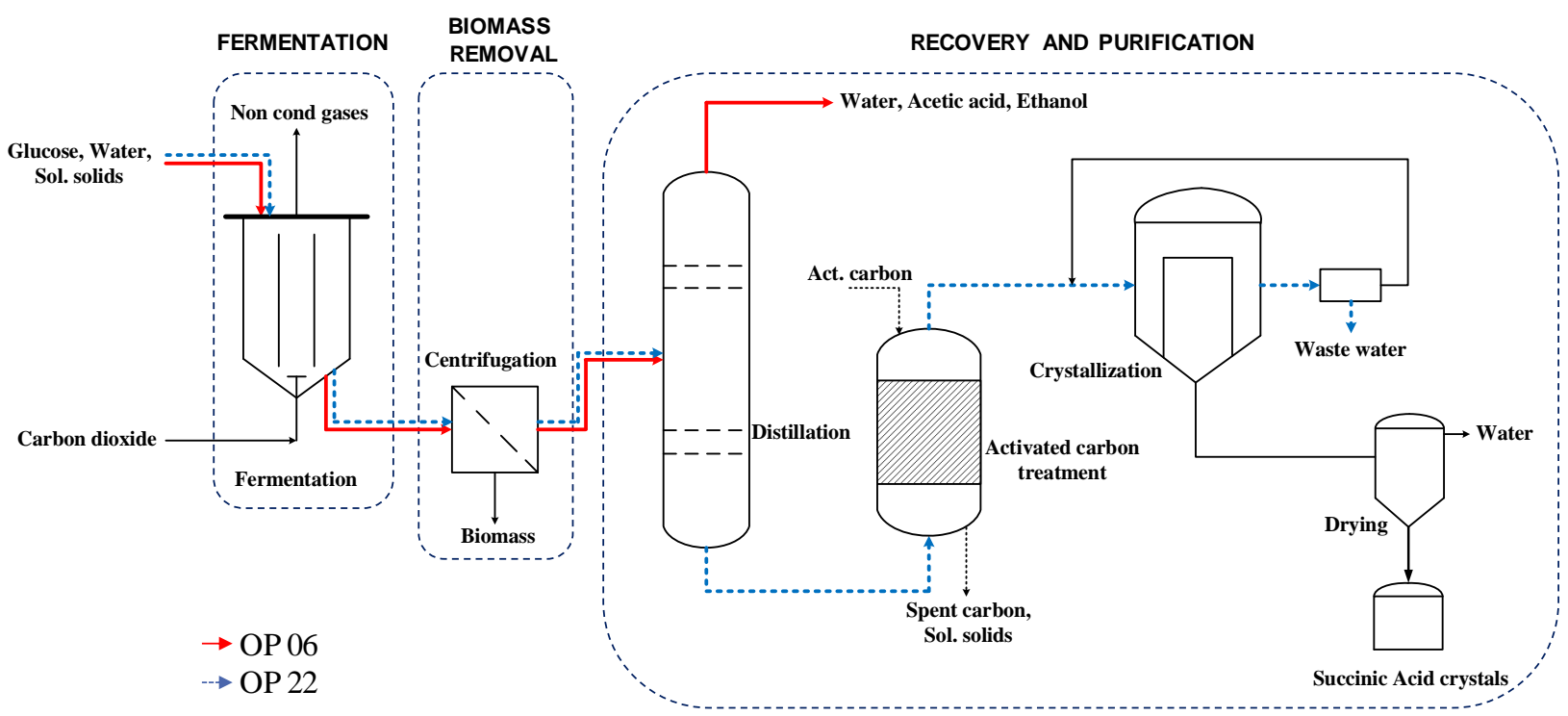

Figure 8: Process flowsheet of selected alternative for bio-succinic acid

\subsubsection{Step 3 - Detailed base case design}

The base case is rigorously simulated using PRO/II and the UNIQUAC model is used for the liquid activity coefficients. Optimized UNIQUAC parameters for the calculation of water-acetic acid VLE system is retrieved from Pirola et al. (2014). Then, the detailed mass and energy balance data along with number of streams, unit operations data is extracted to carry out analysis in the next step. An overview of the key simulation results is given in table 5.

Table 5: Key results from rigorous simulation of Base case

\begin{tabular}{ll}
\hline & Value \\
\hline Succinic acid product $(\mathrm{kg} / \mathrm{h})$ & 3750.40 \\
Succinic acid purity $(\mathrm{wt} . \%)$ & $>99$ \\
Total energy supplied $(\mathrm{MJ} / \mathrm{h})$ & 73240.53 \\
Total energy withdrawn $(\mathrm{MJ} / \mathrm{h})$ & 68875.03 \\
\hline
\end{tabular}

\subsubsection{Step 4 - Detailed base case analysis}

In this step, the detailed analysis in terms of process economics, sustainability and life cycle assessment is performed. In house tools ECON, SustainPro and LCSoft are used to carry out the respective analysis. The 
main results from sustainability analysis performed using SustainPro are shown in table 6. In figure 8, the most critical open paths (OP) identified for potential improvements are highlighted.

23 In OP 06, which follows the compound water is present in excess in the system has a high energy waste cost (EWC). The unit operation mainly belonging to this path is distillation column. This translates to loss of energy in the open path and thus potential to recover or reduce energy consumption during the distillation operation whose objective is to remove unwanted byproducts (ethanol and acetic acid) and concentrate the broth. OP 22 follows the main product succinic acid path ending at crystallizer outlet and has high negative value of MVA and positive value of TVA. This translates to loss of product and potential for improvement in recovery of product.

Table 6: List of critical paths with highest potential for improvement (MVA-Mass vale added, EWCEnergy and waste cost, TVA-Total value added)

\begin{tabular}{cccccc}
\hline \multirow{2}{*}{ Path } & Compound & $\begin{array}{c}\text { Flowrate } \\
\mathrm{kg} / \mathrm{hr}\end{array}$ & $\begin{array}{c}\text { MVA } \\
10^{3} \$ / \mathrm{yr}\end{array}$ & $\begin{array}{c}\text { EWC } \\
10^{3} \$ / \mathrm{yr}\end{array}$ & $\begin{array}{c}\text { TVA } \\
10^{3} \$ / \mathrm{yr}\end{array}$ \\
\hline OP 06 & Water & 19508.4 & - & 449.4 & - \\
OP 22 & Succinic acid & 662.4 & -1493.1 & 611.0 & -2104.0 \\
\hline
\end{tabular}

32

As can be seen in fig 9 a), LCA analysis (using LCSoft) shows that the carbon footprint is highest for the reboiler of the distillation column and as expected, economic analysis performed using ECON (figure 9 b)) shows that the utility cost is highest for the same reboiler.
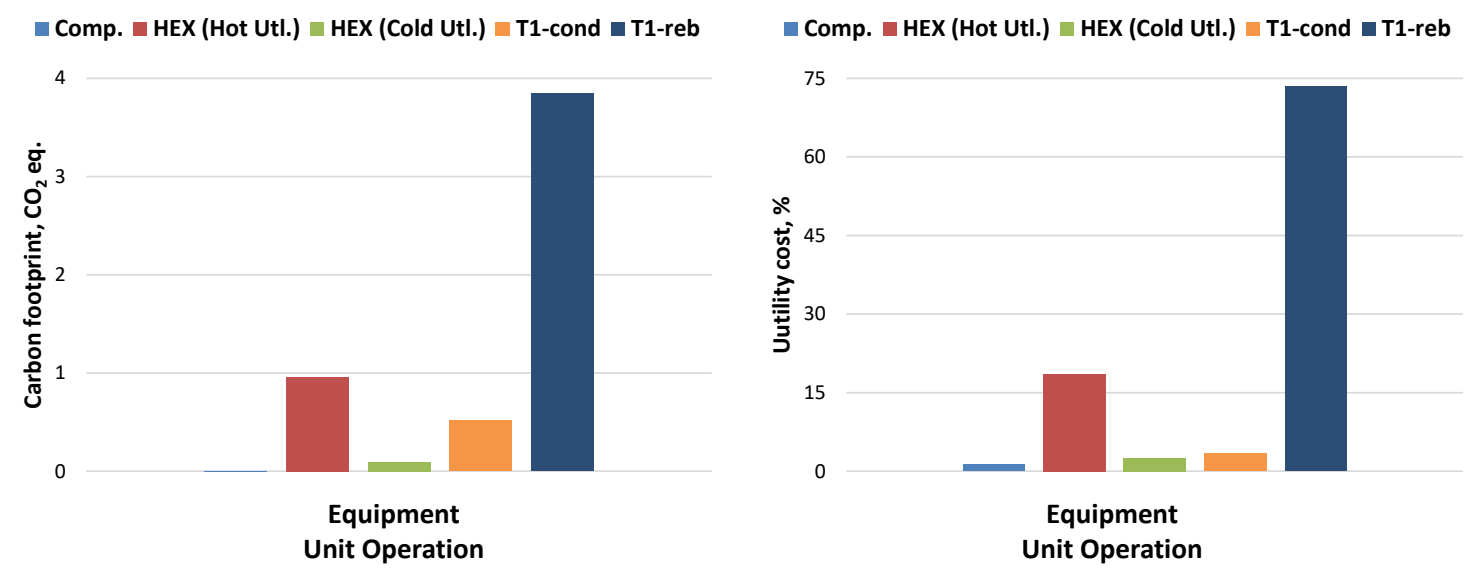

Figure 9: a) LCA analysis (carbon footprint); b) Utility cost distribution

\subsubsection{Step 5 - Identify process hotspots and design targets}

39 The process hotspots identified based on the indicator based analysis in step 4 are shown in table 7. 40 Alongside, the base property and the reason that possibly causes the process hotspot(s) is also mentioned. 


\begin{tabular}{llll}
\hline Indicator values & Base Case property & Reason & Identified Process hotspot \\
\hline Utility cost & & & High energy consumption and/or \\
Material value added (MVA) & demand & \\
Energy waste cost (EWC) & $\begin{array}{l}\text { material and products } \\
\text { recovery }\end{array}$ & $\begin{array}{l}\text { High energy usage-heating } \\
\text { and/or cooling }\end{array}$ & Difficult separation: low driving \\
$\mathrm{CO}_{2}$ equivalent & & & force \\
$\begin{array}{l}\text { Potential environmental } \\
\text { impact (PEI) }\end{array}$ & & \\
\hline
\end{tabular}

42 Further, using database to translate process hotspots, following design targets are identified that are to be 43 achieved in stage 3:

- Reduce energy consumption

- Reduce utility cost

- Improvement in LCA/sustainability indictors

- Unit operation reduction

- Product purity (to be kept at least as base case)

- Production target (to be kept at least as base case)

- Reduce operational cost

- Waste minimization

- Increase product recovery

\subsection{Stage 3 - Innovation}

55

In innovation stage, intensified/hybrid process alternatives are generated by employing phenomena-based intensification methodology that also match the design targets set in stage 2 .

\subsubsection{Step 6-Identification of desirable task and phenomena}

The base case flowsheet based on unit operations is first represented in terms of separation and reaction tasks. The task based flowsheet is shown in figure 10 a). These tasks are further represented in terms of phenomena constituting the initial search sapce. The phenomena based flowsheet generated based on the tasks involved is shwon in figure $10 \mathrm{~b}$ ).

The initial list of phenomena obtained from the phenomena-based flowsheet consists of following PBB's:

M, 2phM, R, C, H, PC(VL), PC(LS), PT(VL), PT(LS), PS(VL), PS(LS) 

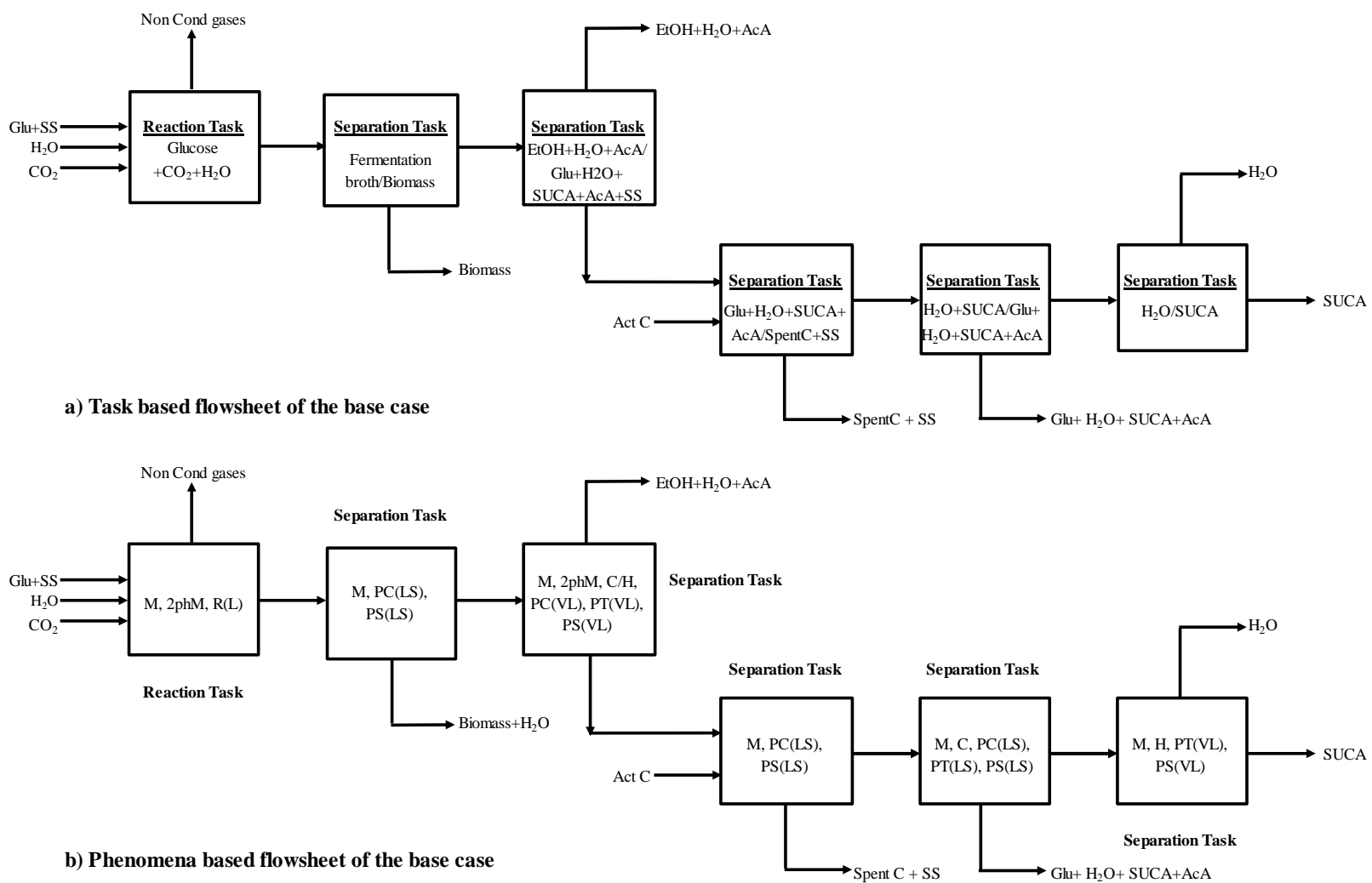

Figure 10: Task and phenomena-based flowsheet for the base case

66 The pure component and mixture property analysis is performed using ICAS (Gani et al., 1997). The binary

67 ratio matrix for key pure component properties is shown in table 8. Here, $\mathrm{H}_{2} \mathrm{O}$ is water, EtOH is ethanol,

68 HOAc is acetic acid and SUCA is succinic acid. Alongside, azeotropic and miscibility analysis of the

69 mixture is also performed and a bianry azeotrope between water and ethanol is identified. This is also pre-

70 conceived from the value of boiling point binary ratio, as the value is close to unity. In this case study, the

71 flow rate of byproducts like ethanol is not high enough Thus, separation of byproducts is not considered

72 in further steps.

73 Table 8: Binary ratio matrix for a selected set of properties

74 ( $r_{i j}$-binary ratio, Tb-normal boiling point $(K)$, Tm-normal melting point $(K)$, SolPar-Solubility parameter $75\left(M_{P a}^{0.5}\right), V d W$-Van der Waals volume $\left(\mathrm{m}^{3} / \mathrm{kmol}\right), R G$-radius of gyration $(\AA), M W$-molecular weight $(\mathrm{g} / \mathrm{mol})$,

$76 \quad$ MV-molar volume $\left.\left(\mathrm{m}^{3} / \mathrm{kmol}\right)\right)$

\begin{tabular}{llllllll}
\hline $\mathbf{r}_{\mathbf{i j}}$ & $\mathbf{T}_{\mathbf{b}}$ & $\mathbf{T}_{\mathbf{m}}$ & SolPar & $\mathbf{V d W}$ & $\mathbf{R G}$ & $\mathbf{M W}$ & $\mathbf{M V}$ \\
\hline $\mathrm{H}_{2} \mathrm{O} / \mathrm{EtOH}$ & 1.06 & 1.72 & 1.83 & 2.58 & 3.67 & 2.56 & 3.24 \\
$\mathrm{H}_{2} \mathrm{O} / \mathrm{HOAc}$ & 1.05 & 1.06 & 2.52 & 2.69 & 4.24 & 3.33 & 3.18 \\
$\mathrm{H}_{2} \mathrm{O} / \mathrm{SUCA}$ & 1.58 & 1.69 & 1.63 & 4.81 & 6.76 & 6.56 & 5.39 \\
\hline
\end{tabular}




\begin{tabular}{llllllll}
\hline EtOH/HOAc & 1.11 & 1.82 & 1.37 & 1.04 & 1.16 & 1.30 & 1.02 \\
EtOH/SUCA & 1.68 & 2.90 & 1.12 & 1.87 & 1.84 & 2.56 & 1.66 \\
HOAc/SUCA & 1.51 & 1.59 & 1.54 & 1.79 & 1.59 & 1.97 & 1.69 \\
\hline
\end{tabular}

77 Additional desirable tasks and PBB's are selected to eliminate the process hotspots from step 5. The 78 desirable separation tasks consists of PT(PVL), PT(VV), PS(VV), PC(LL), PS(LL) PBB's. This is 79 explained as follows. In table 7, the hotspots identified are high energy consumption and difficult 80 separation. The rule for selection is that the high energy consumption or low driving force can be countered 81 by using the separation tasks related to permeability/affinity (Jaksland et al.,1995; Tula et al., 2015; Babi 82 et al., 2015). This is also visible from the binary ratio calculations for solubility parameter, molar volume 83 and Van der Waals volume in table 8. It makes the removal of water feasbile, using separation task related 84 to permeability/affinity. Additionaly as per rules, the D phenomena ia automatically added to additional list 85 of PBB's. These PBB's are added to the initial list and thus the total list consists of following phenomena's:

$86 \mathrm{M}$ (four types - ideal liquid, tubular, rectangular, ideal vapor), 2phM, R(L), C, H, PC(VL), PC(LS), 87 PT(VL), PT(LS), PS(VL), PS(LS), PT(PVL), PT(VV), PS(VV), PC(LL), PS(LL), D

88 The operating window i.e. the range in which PBB's are feasible is shown in table 9.

Table 9: Binary ratio matrix for a selected set of properties

\begin{tabular}{|c|c|}
\hline Phenomena & Operating Window \\
\hline \multirow{2}{*}{$\mathrm{R}$} & $\mathrm{T}_{\text {low }}=273.15 \mathrm{~K}$ (lowest melter) \\
\hline & $\mathrm{T}_{\text {high }}=310.15 \mathrm{~K}$ ( $\mathrm{T}$ for fermentation according to base case) \\
\hline \multirow{2}{*}{$\mathrm{M}_{\mathrm{v}}$} & $\mathrm{T}_{\text {low }}=351.35 \mathrm{~K}$ (lowest boiling azeotrope) \\
\hline & $\mathrm{T}_{\text {high }}=591.00 \mathrm{~K}$ (highest boiler) \\
\hline \multirow{2}{*}{$M_{I d}$} & $\mathrm{~T}_{\text {low }}=159.05 \mathrm{~K}$ (lowest melter) \\
\hline & $\mathrm{T}_{\text {high }}=591.00 \mathrm{~K}$ (highest boiler) \\
\hline \multirow{2}{*}{$2 \mathrm{phM}$} & $\mathrm{T}_{\text {low }}=159.05 \mathrm{~K}$ (lowest melter) \\
\hline & $\mathrm{T}_{\text {high }}=591.00$ (highest boiler) \\
\hline $\mathrm{PC}(\mathrm{VL})$ & V-L present \\
\hline $\mathrm{PC}(\mathrm{LL})$ & L-L present \\
\hline $\mathrm{PC}(\mathrm{LS})$ & L-S present \\
\hline \multirow{2}{*}{ PT(LS) } & $\mathrm{T}_{\text {low }}=159.05 \mathrm{~K}$ (lowest melter) \\
\hline & $\mathrm{T}_{\text {high }}=460.65 \mathrm{~K}$ (highest melter) \\
\hline \multirow{2}{*}{$\mathrm{PT}(\mathrm{VL})$} & $\mathrm{T}_{\text {low }}=351.35 \mathrm{~K}$ (lowest boiling azeotrope) \\
\hline & $\mathrm{T}_{\text {high }}=591.00 \mathrm{~K}$ (highest boiler) \\
\hline PT(PVL) & Component affinity \\
\hline
\end{tabular}




\begin{tabular}{ll} 
PT(VV) & Component affinity \\
PS(LL) & L-L present \\
PS(VL) & V-L present \\
PS(VV) & V-V present (all compounds in vapor phase) \\
PS(LS) & L-S present \\
H & - \\
C & - \\
D & - \\
\hline
\end{tabular}

92 The maximum number of phenomena that can be combined to form an SPB is calculated using the following 93 equation (Lutze et al., 2013; Babi et al., 2015).

$94 \quad n P B B_{\text {Max }}=n P B B-\left(n P B B_{E}-1\right)-\left(n P B B_{M}-1\right)-n P B B_{D}$

95 Here, $\mathrm{nPBB}_{\mathrm{Max}}$ is the maximum number of PBBs within a SPB, nPBB is the total number of PBBs (20 in 96 total), $\mathrm{nPBB}_{\mathrm{E}}\left(\mathrm{C}\right.$ and $\mathrm{H}-2$ in total), $\mathrm{nPBB}_{\mathrm{M}}$ (3 in total, considering rectangular and tubular as flow mixing),

$97 \mathrm{nPBB}_{\mathrm{D}}(1)$ are energy PBBs, mixing PBBs (ideal liquid, rectangular and tubular (flow), ideal vapor) and 98 dividing PBB respectively. Thus, the calculated maximum number of phenomena that can be combined to form an $\mathrm{SPB}, \mathrm{nPBB}_{\mathrm{Max}}$, is calculated to be 16 .

100 Further, total number of SPB's that can be generated is calculated using the following equation (Lutze et 101 al., 2013):

$n S P B_{\text {Max }}=\sum_{k=1}^{n P B B_{\text {Max }}}\left[\frac{(n P B B-1) !}{(n P B B-k-1) ! k !}\right]+1$

The total number of SPBs that can be generated, having a maximum of 16 PBBs is calculated to be 519252 . All the above combinations are not feasible. Thus, connectivity rules are used to identify the feasible SPB's. An example of a connectivity rule is that the cooling $(\mathrm{C})$ and heating $(\mathrm{H}) \mathrm{PBB}$ cannot be present in a single $\mathrm{SPB}$, as it is thermodynamically infeasible. Thus, feasible SPB's are generated assuming 3 types of mixing 107 ideal liquid, tubular and rectangular (flow). A partial list of feasible SPB's generated is shown in table 10.

Table 10: Partial list of feasible SPB's, Ph. Cr. - phase creation

\begin{tabular}{lll}
\hline SPB & Connected PBB & Task they may perform \\
\hline SPB.1 & M & Mixing
\end{tabular}




\begin{tabular}{|c|c|c|}
\hline SPB. 2 & $\mathrm{M}=2 \mathrm{phM}$ & Mixing \\
\hline SPB.3 & $\mathrm{M}=\mathrm{R}$ & Mixing+Reaction \\
\hline SPB.4 & $\mathrm{M}=\mathrm{H}$ & Mixing+Heating \\
\hline SPB.5 & $\mathrm{M}=\mathrm{C}$ & Mixing+Cooling \\
\hline SPB.6 & $\mathrm{M}=\mathrm{R}=\mathrm{H}$ & Mixing+Reaction+Heating \\
\hline SPB.7 & $\mathrm{M}=\mathrm{R}=\mathrm{C}$ & Mixing+Reaction+Cooling \\
\hline SPB.8 & $\mathrm{M}=2 \mathrm{phM}=\mathrm{R}$ & Mixing+Reaction \\
\hline SPB.9 & $\mathrm{M}=2 \mathrm{phM}=\mathrm{C}$ & Mixing+Cooling \\
\hline SPB. 10 & $\mathrm{M}=2 \mathrm{phM}=\mathrm{H}$ & Mixing+Heating \\
\hline SPB.11 & $\mathrm{M}=2 \mathrm{phM}=\mathrm{R}=\mathrm{C}$ & Mixing+Reaction+Cooling \\
\hline SPB. 12 & $\mathrm{M}=2 \mathrm{phM}=\mathrm{R}=\mathrm{H}$ & Mixing+Reaction+Heating \\
\hline SPB.13 & $\mathrm{M}=2 \mathrm{phM}=\mathrm{PC}(\mathrm{VL})=\mathrm{PT}(\mathrm{VL})$ & Mixing+Ph. Cr. \\
\hline SPB.14 & $\mathrm{M}=\mathrm{R}=2 \mathrm{phM}=\mathrm{PC}(\mathrm{VL})=\mathrm{PT}(\mathrm{VL})$ & Mixing+Reaction+Ph. Cr. \\
\hline SPB. 15 & $\mathrm{M}=\mathrm{C}=2 \mathrm{phM}=\mathrm{PC}(\mathrm{VL})=\mathrm{PT}(\mathrm{VL})$ & Mixing+Cooling+Ph. Cr. \\
\hline SPB.16 & $\mathrm{M}=\mathrm{H}=2 \mathrm{phM}=\mathrm{PC}(\mathrm{VL})=\mathrm{PT}(\mathrm{VL})$ & Mixing+Heating+Ph. Cr. \\
\hline SPB.17 & $\mathrm{M}=\mathrm{R}=\mathrm{C}=2 \mathrm{phM}=\mathrm{PC}(\mathrm{VL})=\mathrm{PT}(\mathrm{VL})$ & Mixing+Reaction+Cooling+Ph. Cr. \\
\hline SPB.18 & $\mathrm{M}=\mathrm{R}=\mathrm{H}=2 \mathrm{phM}=\mathrm{PC}(\mathrm{VL})=\mathrm{PT}(\mathrm{VL})$ & Mixing+Reaction+Heating+Ph. Cr. \\
\hline SPB.19 & $\mathrm{M}=\mathrm{H}=\mathrm{PT}(\mathrm{VL})=\mathrm{PS}(\mathrm{VL})$ & Mixing+Heating+Separation \\
\hline SPB.20 & $\mathrm{M}=\mathrm{R}=\mathrm{H}=\mathrm{PT}(\mathrm{VL})=\mathrm{PS}(\mathrm{VL})$ & Mixing+Reaction+Heating+Separation \\
\hline SPB.21 & $\mathrm{M}=2 \mathrm{phM}=\mathrm{PC}(\mathrm{VL})=\mathrm{PT}(\mathrm{VL})=\mathrm{PS}(\mathrm{VL})$ & Mixing+Separation \\
\hline SPB.22 & $\mathrm{M}=\mathrm{H}=2 \mathrm{phM}=\mathrm{PC}(\mathrm{VL})=\mathrm{PT}(\mathrm{VL})=\mathrm{PS}(\mathrm{VL})$ & Mixing+Heating+Separation \\
\hline SPB.23 & $\mathrm{M}=\mathrm{C}=2 \mathrm{phM}=\mathrm{PC}(\mathrm{VL})=\mathrm{PT}(\mathrm{VL})=\mathrm{PS}(\mathrm{VL})$ & Mixing+Cooling+Separation \\
\hline SPB.24 & $\mathrm{M}=\mathrm{R}=2 \mathrm{phM}=\mathrm{PC}(\mathrm{VL})=\mathrm{PT}(\mathrm{VL})=\mathrm{PS}(\mathrm{VL})$ & Mixing+Reaction+Separation \\
\hline SPB. 25 & $\mathrm{M}=\mathrm{R}=\mathrm{H}=2 \mathrm{phM}=\mathrm{PC}(\mathrm{VL})=\mathrm{PT}(\mathrm{VL})=\mathrm{PS}(\mathrm{VL})$ & Mixing+Reaction+Heating+Separation \\
\hline SPB.26 & $\mathrm{M}=\mathrm{R}=\mathrm{C}=2 \mathrm{phM}=\mathrm{PC}(\mathrm{VL})=\mathrm{PT}(\mathrm{VL})=\mathrm{PS}(\mathrm{VL})$ & Mixing+Reaction+Cooling+Separation \\
\hline SPB.27 & $\mathrm{M}=2 \mathrm{phM}=\mathrm{PC}(\mathrm{VL})=\mathrm{PT}(\mathrm{PVL})=\mathrm{PS}(\mathrm{VL})$ & Mixing+Separation \\
\hline SPB.28 & $\mathrm{M}=\mathrm{H}=2 \mathrm{phM}=\mathrm{PC}(\mathrm{VL})=\mathrm{PT}(\mathrm{PVL})=\mathrm{PS}(\mathrm{VL})$ & Mixing+Heating+Separation \\
\hline SPB.29 & $\mathrm{M}=\mathrm{C}=2 \mathrm{phM}=\mathrm{PC}(\mathrm{VL})=\mathrm{PT}(\mathrm{PVL})=\mathrm{PS}(\mathrm{VL})$ & Mixing+Cooling+Separation \\
\hline SPB.30 & $\mathrm{M}=\mathrm{R}=2 \mathrm{phM}=\mathrm{PC}(\mathrm{VL})=\mathrm{PT}(\mathrm{PVL})=\mathrm{PS}(\mathrm{VL})$ & Mixing+Reaction+Separation \\
\hline SPB.31 & $\mathrm{M}=\mathrm{R}=\mathrm{H}=2 \mathrm{phM}=\mathrm{PC}(\mathrm{VL})=\mathrm{PT}(\mathrm{PVL})=\mathrm{PS}(\mathrm{VL})$ & Mixing+Reaction+Heating+Separation \\
\hline SPB.32 & $\mathrm{M}=\mathrm{R}=\mathrm{C}=2 \mathrm{phM}=\mathrm{PC}(\mathrm{VL})=\mathrm{PT}(\mathrm{PVL})=\mathrm{PS}(\mathrm{VL})$ & Mixing+Reaction+Cooling+Separation \\
\hline SPB.33 & $\mathrm{M}=2 \mathrm{phM}=\mathrm{PT}(\mathrm{VV})=\mathrm{PS}(\mathrm{VV})$ & Mixing+Separation \\
\hline SPB.34 & $\mathrm{M}=\mathrm{C}=2 \mathrm{phM}=\mathrm{PT}(\mathrm{VV})=\mathrm{PS}(\mathrm{VV})$ & Mixing+Cooling+Separation \\
\hline SPB.35 & $\mathrm{M}=\mathrm{H}=2 \mathrm{phM}=\mathrm{PT}(\mathrm{VV})=\mathrm{PS}(\mathrm{VV})$ & Mixing+Heating+Separation \\
\hline SPB.36 & $\mathrm{M}=\mathrm{R}=2 \mathrm{phM}=\mathrm{PT}(\mathrm{VV})=\mathrm{PS}(\mathrm{VV})$ & Mixing+Reaction+Separation \\
\hline SPB.37 & $\mathrm{M}=\mathrm{R}=\mathrm{C}=2 \mathrm{phM}=\mathrm{PT}(\mathrm{VV})=\mathrm{PS}(\mathrm{VV})$ & Mixing+Reaction+Cooling+Separation \\
\hline SPB... & $\cdots$ & $\cdots$ \\
\hline SPB. 214 & $\mathrm{D}$ & Stream division \\
\hline
\end{tabular}

110 Further, a task-based superstructure that represents all possible (feasible and infeasible) combinations of 111 tasks from fermentation reaction to separation steps to recover pure compounds is shown in figure 11. The 112 key for compounds alphabet is given below the figure. Compounds A, B and C are non-condensable gases 
that are removed from fermenter only and thus are not considered for the task based superstructure. Raw materials must react in presence of bacteria for a fermentation to take place and produce products, thus the

115 first task is the reaction task. The first separation task after fermentation is generally broth clarification in 116 bio processes i.e. biomass removal so as to avoid any separation problems. Using the pure component 117 property analysis, second separation task is removal of unwanted light compounds along with water, which 118 are byproducts ethanol and acetic acid. Further, presence of impurities like soluble solids in fermentation 119 can cause problems in purification, thus third separation task is to remove them, and they are preferred after 120 water removal because of less working volume as water is the most abundant compound in the process. The 121 fourth separation task is removal of glucose and water from the clear concentrated solution. The last separation task is to get pure succinic acid and remove any remaining moisture (water).

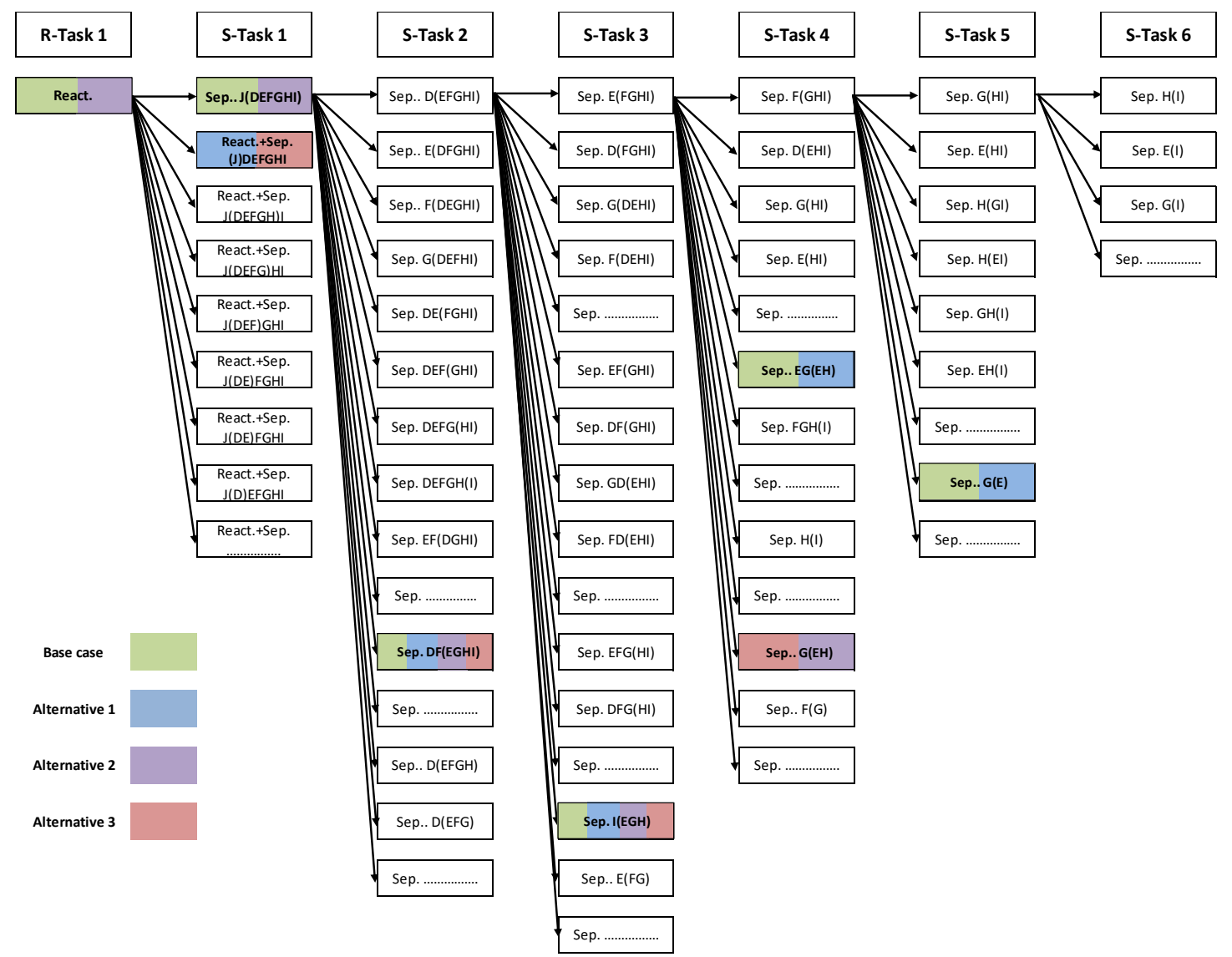
H- Glucose, I - Soluble solids, J - Biomass)

128 The base case and identified task-based flowsheets with and without task merging are highlighted in taskbased superstructure shown in figure 11. The flowsheet generation is explained as follows (tables 11-13): 
The fermentation feed (similar to the base case) consists of glucose and $\mathrm{CO}_{2}$ along with other necessary components and nutrients. The fermentation reaction does not go to full completion i.e. all main raw material does not get consumed, therefore, the fermenter outlet contains a mixture of raw materials, products and byproducts. Also, as the main raw materials glucose and $\mathrm{CO}_{2}$ (consumed in soluble form) are reacting in liquid phase thus a basic structure containing ' $R(L)$ ' $P B B$ is selected to perform the reaction task. Further, cell removal or broth clarification is a mandatory step after fermentation and for that, a basic structure with same set of phenomena as base case 'PS(LS)' is considered. Similarly, all the basic structures are identified for the tasks and are shown in table 11. These basic structures are formed in a way that they satisfy the identified reaction and separation tasks.

- Flowsheet alternative 1: The merging of reaction and separation tasks is considered and found to be feasible because SPBs that perform simultaneous reaction and separation (see, for example, Table 10, SPB.14) can be combined to form basic structures that perform these two tasks simultaneously. Therefore, the merging of R-Task and S-Task 1 is considered. In this alternative, starting with the first task of reaction, the second task, cell removal or clarification of broth could be combined to obtain a new basic structure of phenomena's that perform two tasks as shown in table 12. The task based flowsheet for alternative 1 is highlighted with blue color in figure 11. Further, the task based flowsheet is translated to unit operation based flowsheet. In this alternative, the combined reaction and separation task are translated to membrane reactor (bio). In this unit operation, the fermentation broth is clarified i.e. the reaction product is removed continuously and the cell culture remains in the membrane bioreactor leading to increased cell concentration and product yield, which is also observed by Wang et al. (2014). According to Wang et al. (2014), using membrane based fermentation and separation system the problem of succinic acid inhibition is alleviated by removing acids and thus yielding better results. The unit operation based flowsheet for alternative 1 is shown in figure 12a.

Flowsheet alternative 2: In this alternative again, the merging of tasks is considered and the integration of basic structures for the last two separation tasks is found to be feasible as basic structure for both the separation tasks share the similar set of SPB with PS(LS) PBB. Therefore, merging of S-Task 4 and S-Task 5 is performed to generate a new feasible basic structure identified from the database. Here, the performance of the task is enhanced by PS(LL) PBB from the list of phenomena (table 13). The task based flowsheet for alternative 2 is highlighted with purple color in figure 11. The combination of separation basic structures is translated to membrane crystallizer using a reverse osmosis membrane (Kuhn et al., 2009). Kuhn et al. (2009) showed that the crystallization performance of organic acids can be significantly improved using RO membranes. The corresponding unit operation based flowsheet for this alternative is shown in figure $12 \mathrm{~b}$. 


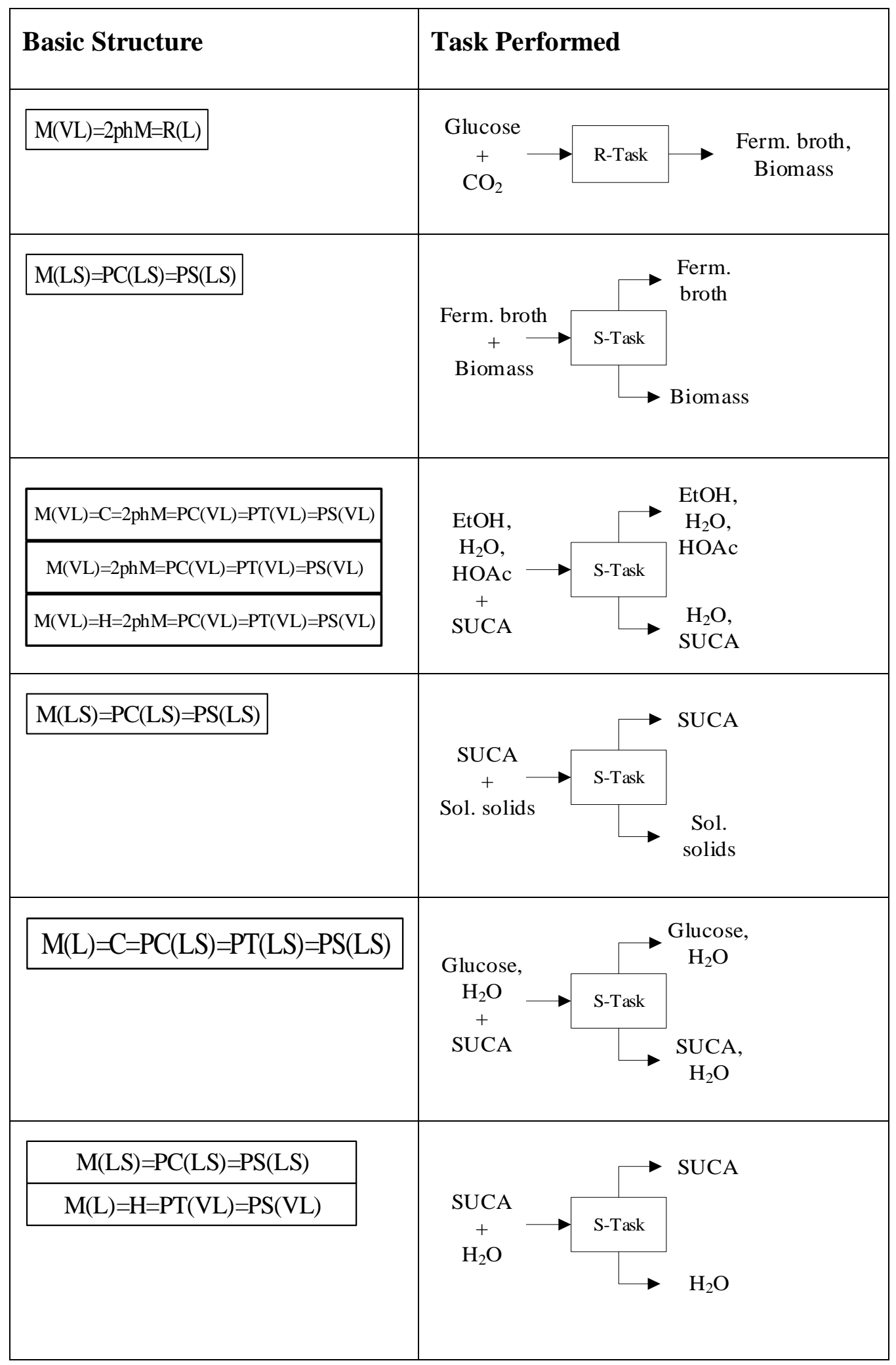




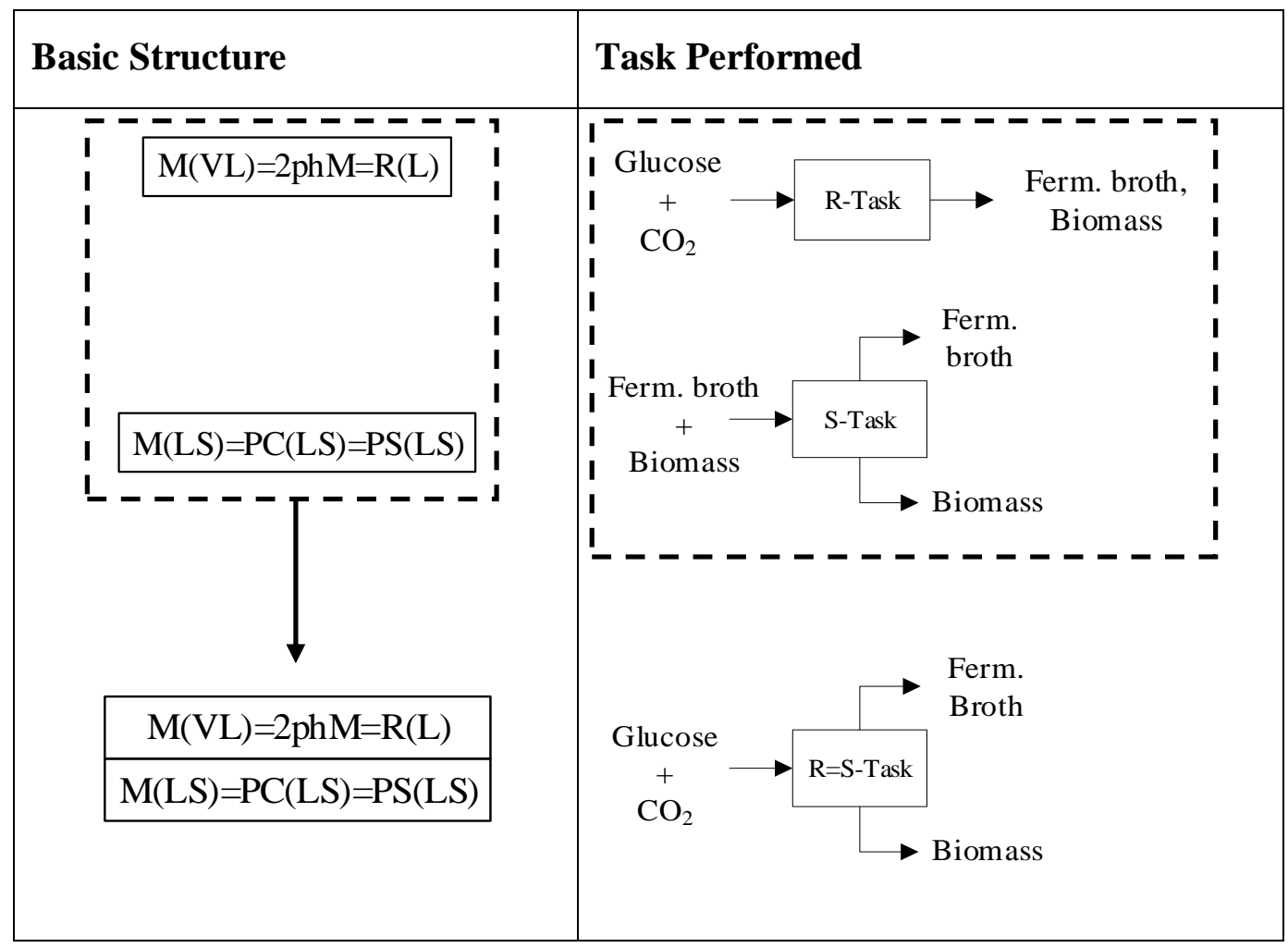

Table 13: Identified basic structure for flowsheet alternative 2 and 3

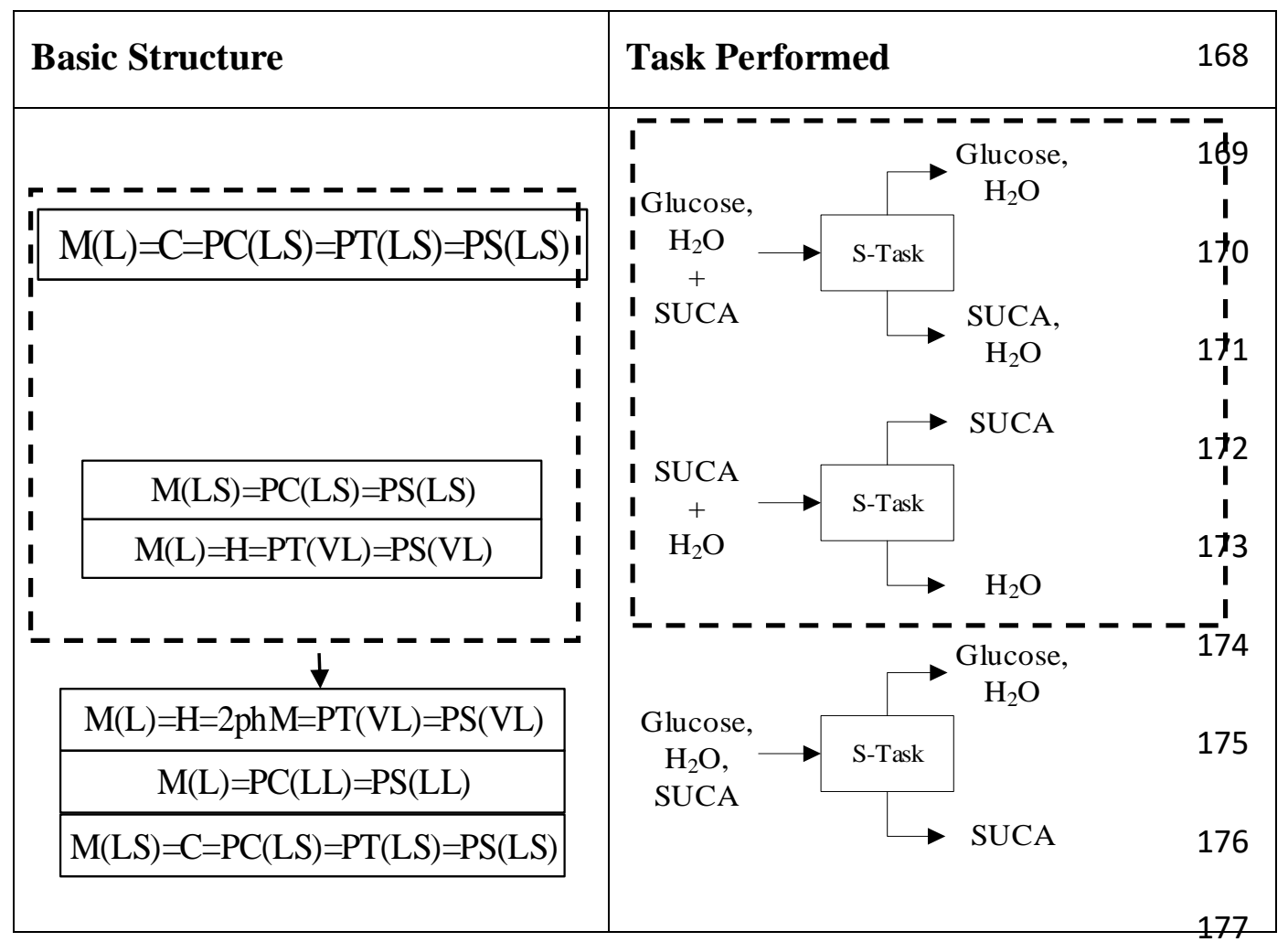




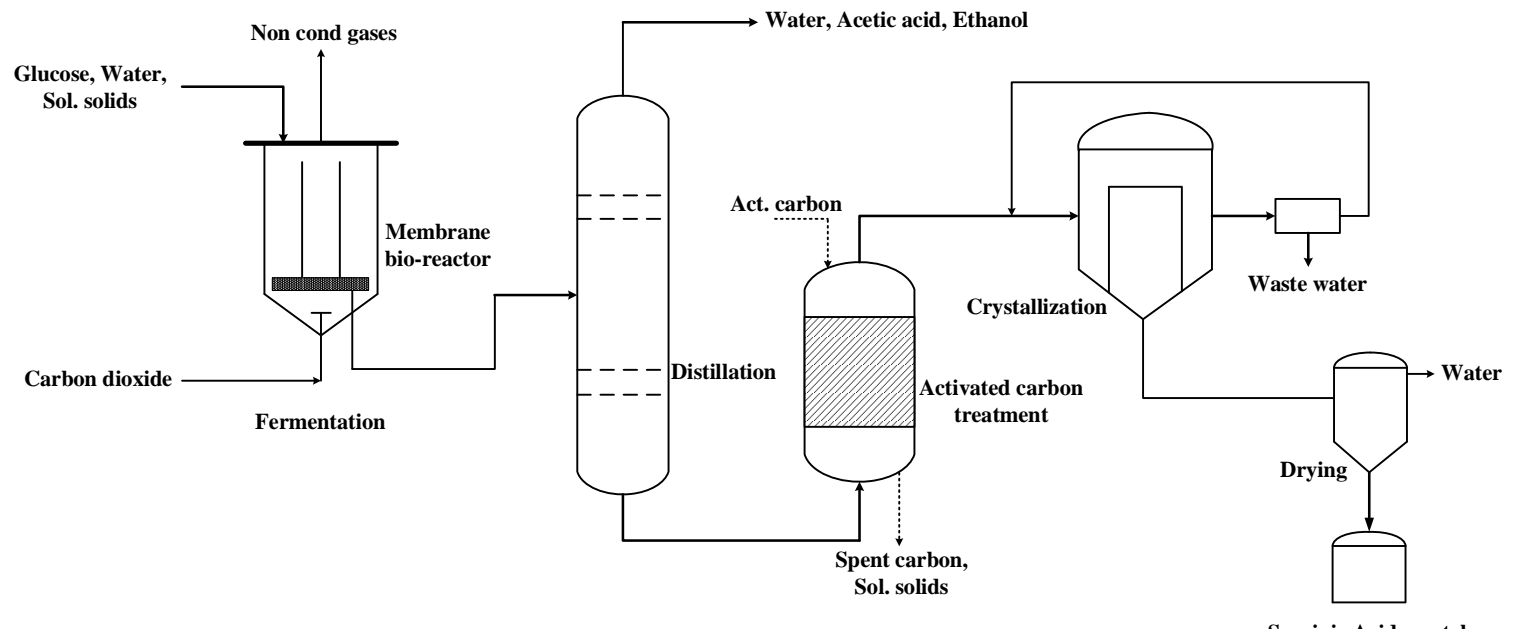

a) Flowsheet alternative 1

$\longrightarrow$ Water, Acetic acid, Ethanol

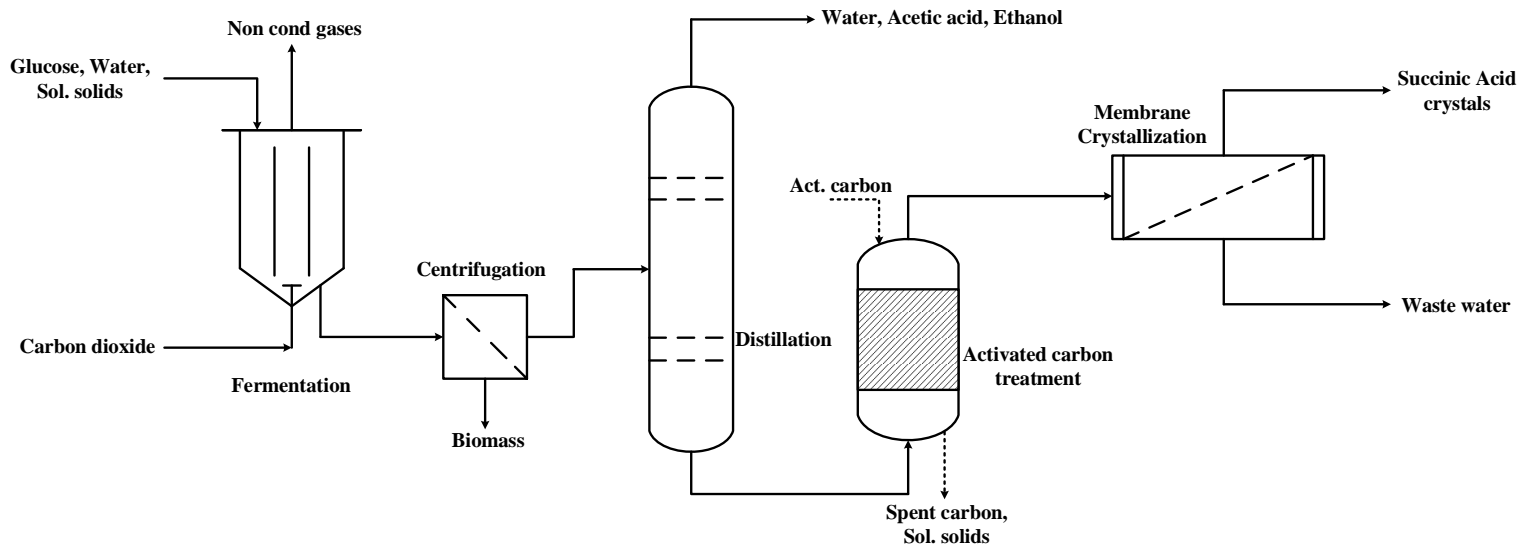

b) Flowsheet alternative 2

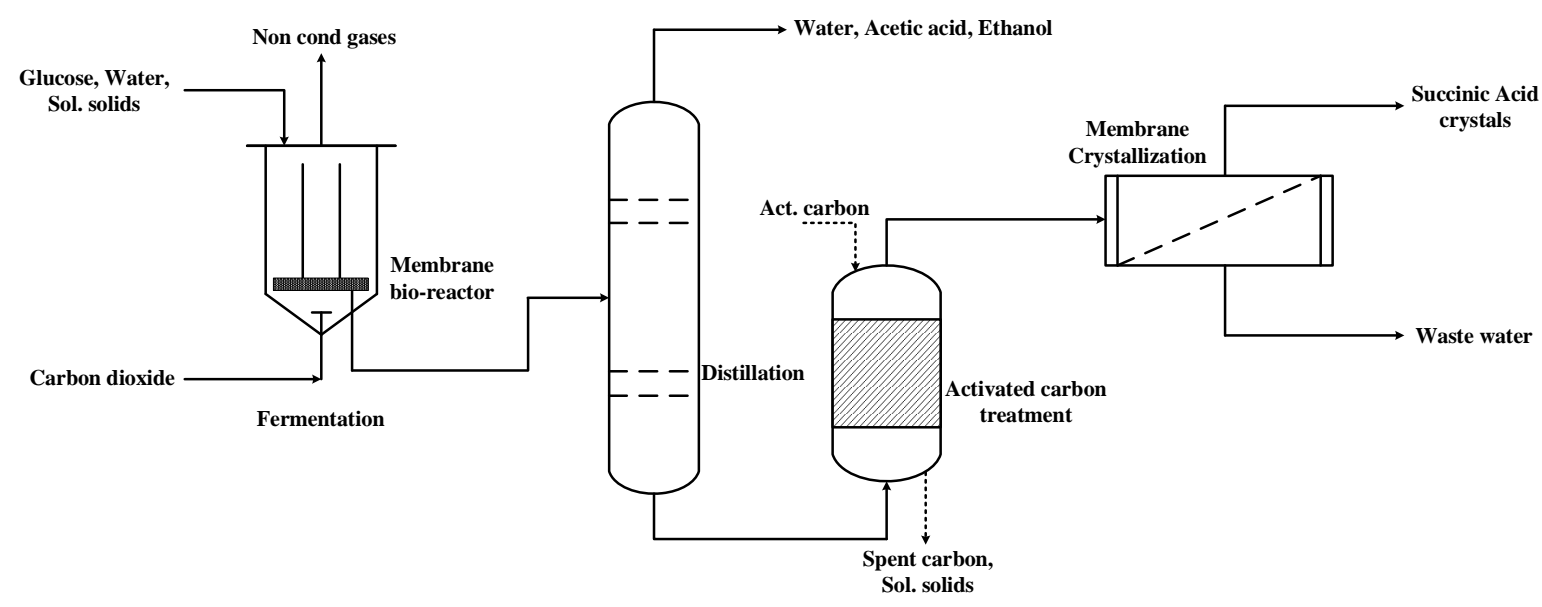

c) Flowsheet alternative 3

Figure 12: The generated flowsheet alternatives for the production of bio-succinic acid 
- Flowsheet alternative 3: This alternative is combination of alternative 1 and 2, where combination of reaction and adjacent separation task, two last separation task is considered to generate new basic structures. The task based flowsheet is highlighted with red color in table 11 and corresponding unit operation based flowsheet is shown in figure 12c.

\subsubsection{Step 7 - Intensified flowsheets verification and selection}

191 The flowsheet alternatives generated in step 7 are verified by performing simulations and are analyzed in 192 terms of economics, sustainability parameters and LCA and then screened using the predefined 193 performance criteria. The results and comparison of the analysis for the three feasible alternative process 194 designs is given in table 14.

195 The three flowsheet alternatives are all better than the base case design with respect to economic, 196 sustainability and LCA factors. Flowsheet alternative 3 shows the best values of the performance 197 parameters and also has lowest carbon footprint. For each of the alternatives the product purity has been 198 kept or improved from the base case while maintaining the production target. The number of unit operations 199 have been reduced in all the alternatives in comparison to the base case (table 14).

Table 14: Analysis results for base case and generated intensified alternatives

\begin{tabular}{|c|c|c|c|c|c|}
\hline & Parameter & Base Case & Alternative 1 & Alternative 2 & Alternative 3 \\
\hline \multirow[t]{9}{*}{ General results } & Succinic Acid Production (kt/y) & 30.00 & 30.31 & 32.32 & 32.65 \\
\hline & Succinic acid purity (wt. \%) & $>99$ & $>99$ & $>99$ & $>99$ \\
\hline & Utility Cost (M\$/y) & 4.95 & 4.13 & 4.98 & 4.16 \\
\hline & Raw material cost $(\mathrm{M} \$ / \mathrm{y})$ & 29.04 & 29,09 & 29.04 & 29.09 \\
\hline & Raw material (Glucose) loss (kt/y) & 1.49 & 1.49 & 1.49 & 1.49 \\
\hline & Total Process water (kt/y) & $13,534.07$ & $11,447.73$ & $13,534.07$ & $11,447.73$ \\
\hline & Total Energy supplied (MJ/hr) & $73,240.53$ & $61,243.39$ & $73,245.11$ & $61,241.88$ \\
\hline & Total energy withdrawn (MJ/hr) & $68,875.08$ & $57,951.47$ & $68,875.08$ & $57,951.47$ \\
\hline & Number of unit operations & 6 & 5 & 5 & 4 \\
\hline \multirow[t]{4}{*}{ Performance metrics } & Product (kg/kg main RM) & 0.86 & 0.87 & 0.92 & 0.93 \\
\hline & Utility cost ( $\$ / \mathrm{kg}$ product $)$ & 0.16 & 0.14 & 0.15 & 0.13 \\
\hline & RM Cost (\$/kg product) & 0.97 & 0.96 & 0.90 & 0.89 \\
\hline & Product sale $(\$ / y)$ & $8,58,09,289$ & $8,66,76,411$ & $9,24,46,064$ & $9,33,80,221$ \\
\hline \multirow[t]{4}{*}{ LCA results } & GWP $\left(\mathrm{CO}_{2}\right.$ eq. $)$ & 5.41 & 4.48 & 5.02 & 4.16 \\
\hline & HTPI (1/LD50) & $2.66 \mathrm{E}-04$ & $2.20 \mathrm{E}-04$ & $2.47 \mathrm{E}-04$ & $2.04 \mathrm{E}-04$ \\
\hline & PCOP & $1.50 \mathrm{E}-01$ & $1.24 \mathrm{E}-01$ & $1.39 \mathrm{E}-01$ & $1.15 \mathrm{E}-01$ \\
\hline & HTC (kg benzene eq.) & $3.74 \mathrm{E}+00$ & $3.10 \mathrm{E}+00$ & $3.48 \mathrm{E}+00$ & $2.87 \mathrm{E}+00$ \\
\hline
\end{tabular}


The uncertainty analysis based on the original economic values was carried out for the economic performance parameters mentioned in table 14 . According to this analysis, $\pm 10 \%$ change in the original raw material and utility cost brings $\pm 10 \%$ change in $\$ / \mathrm{kg}$ of product for raw material and utility. Similar effect is observed on product sales with change in product cost.

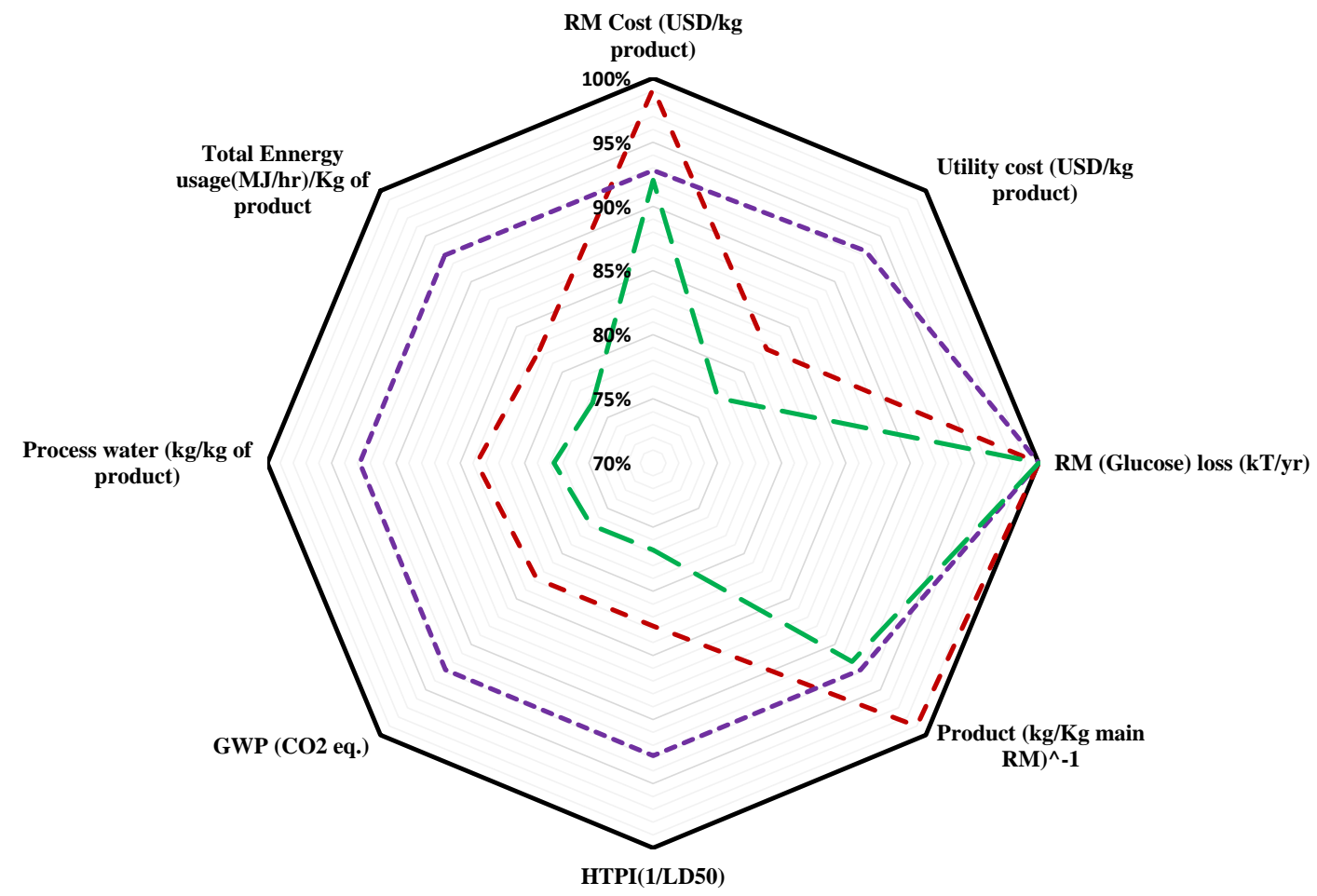

- Base Case $\quad$ - Alternative $1 \quad \ldots$ Alternative $2 \quad$ - Alternative 3

Figure 13: Comparison of Economics and LCA improvements relative to the base case (RM: raw material, HTPI: Human toxicity potential by ingestion, GWP: Global warming potential)

The result of analysis is represented in terms of a radar plot as shown in figure 13. The radar plot confirms that the intensified alternatives are more sustainable and non-trade-off, in terms of the selected performance criteria. Here, the outer boundary of the plot represents the base case design while all the more sustainable intensified alternatives should be within the boundary. The values are calculated by taking percentage ratios of different factors with respect to the base case except profit where inverse ratio has been taken.

\section{Summary - Case study}

A brief summary of bio-succinic acid case study utilizing $\mathrm{CO}_{2}$, solved using the systematic framework is shown in figure 14. The results are shown across 3 stages and how the process alternatives are identified using reduction and expansion of search space and alternatives. More than 11,500 alternatives are generated 
at the synthesis stage using the superstructure network optimization based approach out of which more than 2,600 alternatives are found feasible along with existing routes. The optimal processing route is identified as a novel process alternative to produce bio-succinic acid. The selected alternative is then designed and analyzed in detail to identify process hotspots and set targets for improvement. In the innovation stage, an extended phenomena based synthesis approach was applied to generate 3 intensified alternatives that consists of hybrid/intensified unit operations. These are generated using a rule based methodology to combine phenomena to generate innovative alternatives. The 3 alternatives are more sustainable and economic than the base case for example resulting in nearly $22 \%$ reduction in utility cost and $23 \%$ reduction in the global warming potential for the best alternative (alternative 3), employing membrane bioreactor and membrane crystallizer. As developed, the extended framework is generic and can be applied to chemical and biochemical processes and the results generated shows importance of PI and hybrid/intensified equipment to generate more sustainable process alternatives.

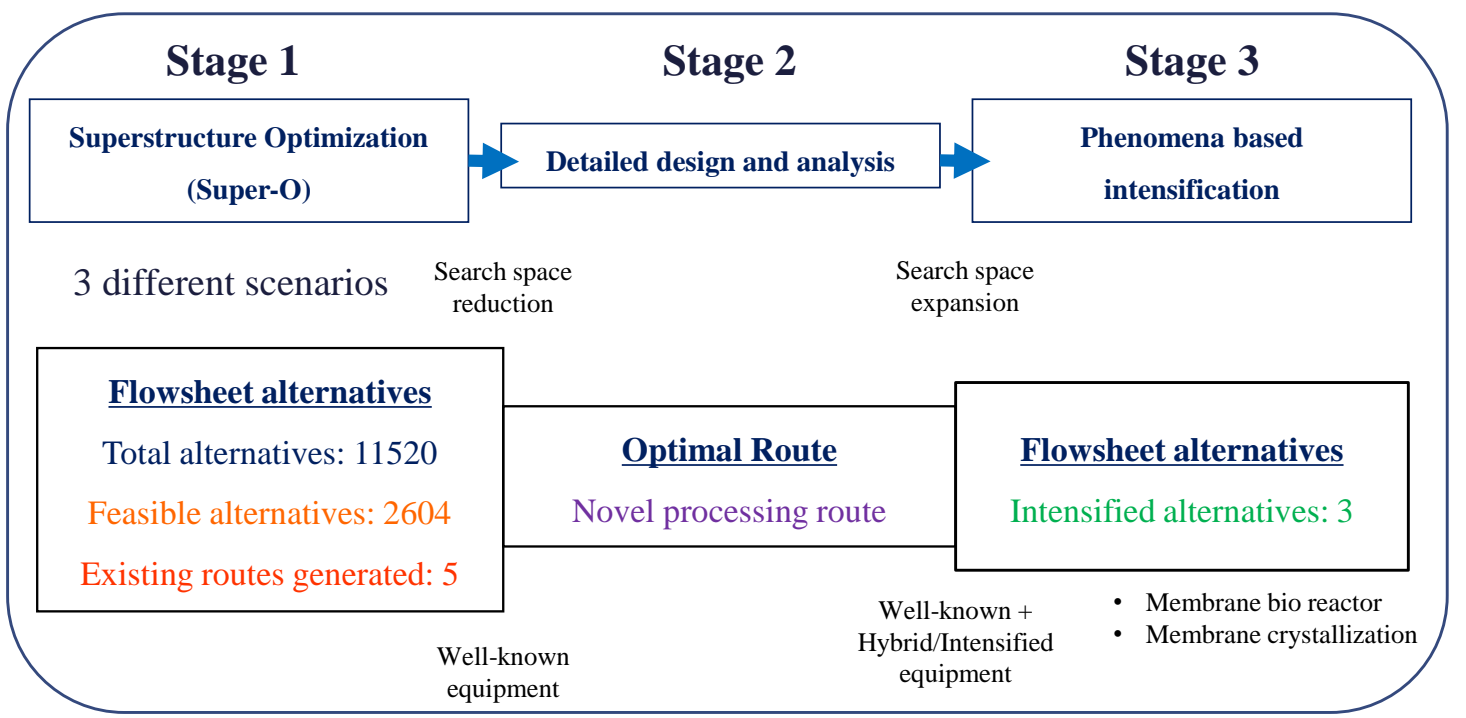

Figure 14: Summary of framework results at different stages for bio-succinic acid case study

\section{Conclusion}

The potential of process intensification to improve the processes has been shown through a systematic framework. An integration of process synthesis and process intensification allows access to a wide range of search space. This is because it operates from the highest scale i.e. unit operation to the lowest scale of phenomena, which are combined in many different ways to generate innovative solutions. The developed systematic framework provides the means to identify, to generate and to evaluate intensified flowsheet options. The framework is computer aided as different software tools are used to achieve the objectives at different steps across all stages. The framework is multi stage, as it has 3 different stages, multi scale as it is operated at 3 different scales of unit operation, task and phenomena and flexible in the way that it can be 
240 applied at any stage if required information is available. The framework has further been extended to

241 increase the flexibility and ability to handle a wide range of applications. The considered in this work

242 application case study (production of bio succinic acid) of the extended framework shows that, more

243 sustainable, non-trade off intensified process alternatives including hybrid/intensified unit operations can

244 be generated.

245 Acknowledgement

246 The authors would like to acknowledge for $\mathrm{PhD}$ scholarship and financial support from Chemical and

247 Biochemical Engineering Department and KT Consortium of Technical University of Denmark.

248

249

250

251

252

253

254

255

256

257

258

259

260

261

262

263

264

265 


\section{References}

267 Agreda V. H., Partin L. R. \& Heise W. H., 1990. High-purity methyl acetate via reactive distillation. Chemical 268 Engineering Prog 86(2):40-46.

269

Anxionnaz, Z., Cabassud, M., Gourdon, C. \& Tochon, P., 2008. Heat exchanger/reactors (HEX reactors): concepts, technologies: state-of-the-art. Chemical Engineering Proc: Process Intensification, 47(12), 2029-2050.

Arizmendi-Sánchez, J.A. and Sharratt, P.N., 2008. Phenomena-based modularisation of chemical process models to approach intensive options. Chemical Engineering Journal, 135(1-2), pp.83-94.

AspenPlus, http://www.aspentech.com (accessed 08 November, 2018).

Asprion, N. and Kaibel, G., 2010. Dividing wall columns: fundamentals and recent advances. Chemical Engineering and Processing: Process Intensification, 49(2), pp.139-146.

Babi, D. K., Holtbruegge, J., Lutze, P., Górak, A., Woodley, J. M. \& Gani, R., 2015. Sustainable process synthesisintensification. Computers \& Chemical Engineering, 81, 218-244.

Babi, D.K. and Gani, R., 2014. Hybrid distillation schemes: design, analysis, and application. In Distillation (pp. 357381).

Bechthold, I., Bretz, K., Kabasci, S., Kopitzky, R. and Springer, A., 2008. Succinic acid: a new platform chemical for biobased polymers from renewable resources. Chemical engineering \& technology, 31(5), pp.647-654.

Bernier, R.L., Dunuwila, D., Cockrem, M.C., Fruchey, O.S., Keen, B.T., Albin, B.A., Dombek, B.D. and Clinton, N.A., Bioamber Sas, 2013. Processes for purification of succinic acid via distillation. WO2013/088239A2.

Bertran, M.O., Frauzem, R., Sanchez-Arcilla, A.S., Zhang, L., Woodley, J.M. and Gani, R., 2017. A generic methodology for processing route synthesis and design based on superstructure optimization. Computers \& Chemical Engineering, 106, pp.892-910.

Bessling, B., Schembecker, G. and Simmrock, K.H., 1997. Design of processes with reactive distillation line diagrams. Industrial \& engineering chemistry research, 36(8), pp.3032-3042.

Caballero, J.A. and Grossmann, I.E., 2004. Design of distillation sequences: from conventional to fully thermally coupled distillation systems. Computers \& chemical engineering, 28(11), pp.2307-2329.

Calabro, V., Jiao, B. L., \& Drioli, E., 1994.Theoretical and experimental study on membrane` distillation in the concentration of orange juice. Industrial \& Engineering Chemistry Research 33 (7), 1803-1808

Carvalho, A., Matos, H.A. and Gani, R., 2013. SustainPro-A tool for systematic process analysis, generation and evaluation of sustainable design alternatives. Computers \& Chemical Engineering, 50, pp.8-27.

Cavani, F., Albonetti, S., Basile, F. and Gandini, A., 2016. Chemicals and fuels from bio-based building blocks. John Wiley \& Sons.

Chen, Q. and Grossmann, I.E., 2017. Recent developments and challenges in optimization-based process synthesis. Annual review of chemical and biomolecular engineering, 8, pp.249-283.

Choi, S., Song, C.W., Shin, J.H. and Lee, S.Y., 2015. Biorefineries for the production of top building block chemicals and their derivatives. Metabolic engineering, 28, pp.223-239. 
Choi, S., Song, H., Lim, S.W., Kim, T.Y., Ahn, J.H., Lee, J.W., Lee, M.H. and Lee, S.Y., 2016. Highly selective production of succinic acid by metabolically engineered Mannheimia succiniciproducens and its efficient purification. Biotechnology and bioengineering, 113(10), pp.2168-2177.

Costs of doing business in Thailand, (2014), http://www.thaiembassy.org/dakar/contents/files/business-20150617184429-264724.pdf, accessed in 2017.

da Cruz, F.E. and Manousiouthakis, V.I., 2017. Process intensification of reactive separator networks through the IDEAS conceptual framework. Computers \& Chemical Engineering, 105, pp.39-55.

Datta, R., Glassner, D.A., Jain, M.K. and Roy, J.R.V., Michigan Biotechnology Institute A Michigan Corp and Michigan Biotechnology Institute East Lansing Michigan A Michigan Corp, 1992. Fermentation and purification process for succinic acid. U.S. Patent 5,168,055A.

Demirel, S. E., Li, J. \& Hasan, M. F., 2017. Systematic process intensification using building blocks. Computers \& Chemical Engineering 105: 2-38.

DOE, U., 2015. Quadrennial technology review 2015-Chapter 6: Innovating clean energy technologies in advanced manufacturing. Washington, DC: US DOE.

Donnelly, M.I., Millard, C.S., Chen, M.J., Rathke, J.W. and Clark, D.P., 1998. A novel fermentation pathway in an Escherichia coli mutant producing succinic acid, acetic acid, and ethanol. In Biotechnology for Fuels and Chemicals (pp. 187-198). Humana Press, Totowa, NJ.

Freund, H. and Sundmacher, K., 2008. Towards a methodology for the systematic analysis and design of efficient chemical processes: Part 1. From unit operations to elementary process functions. Chemical Engineering and Processing: Process Intensification, 47(12), pp.2051-2060.

Gallucci, F., Tosti, S. \& Basile, A., 2008. Pd-Ag tubular membrane reactors for methane dry reforming: a reactive method for $\mathrm{CO}_{2}$ consumption and $\mathrm{H} 2$ production. Journal of Membrane Science, 317(1), 96-105.

GAMS Development Corporation, 2012. General Algebraic Modeling System (GAMS) Release 23.9.5.

Gani, R., Hytoft, G., Jaksland, C., \& Jensen, A. K. (1997). An integrated computer aid-ed system for integrated design of chemical processes. Computers \& Chemical Engineering, 21(10), 1135-1146.

Gerberding, S.J. and Singh, R., Gerberding Steven J, 2012. Purification of succinic acid from the fermentation broth containing ammonium succinate. U.S. Patent $0,289,742$.

Glassner, D.A. and Datta, R., Michigan Biotechnology Institute A Corp Of Mi, 1992. Process for the production and purification of succinic acid. U.S. Patent 5,143,834A.

Graaf, V.D.M.J., Valianpoer, F., Fiey, G., Delattre, L. and Schulten, E.A.M., 2011. Process for the crystallization of succinic acid. WO2011/064151A1.

Grossmann, I. E. (2012). Advances in mathematical programming models for enterprise-wide optimization. Computers \& Chemical Engineering, 47, 2-18.

Guettler, M.V., Jain, M.K. and Rumler, D., Michigan Biotechnology Institute, 1996. Method for making succinic acid, bacterial variants for use in the process, and methods for obtaining variants. U.S. Patent 5,573,931.

Guettler, M.V., Jain, M.K. and Soni, B.K., Michigan Biotechnology Institute, 1998. Process for making succinic acid, microorganisms for use in the process and methods of obtaining the microorganisms. U.S. Patent 5,723,322. 
Guettler, M.V., Rumler, D. and Jain, M.K., 1999. Actinobacillus succinogenes sp. nov., a novel succinic-acidproducing strain from the bovine rumen. International Journal of Systematic and Evolutionary Microbiology, 49(1), pp.207-216.

Halvorsen, I.J. and Skogestad, S., 2011. Energy efficient distillation. Journal of Natural Gas Science and Engineering, 3(4), pp.571-580.

Harper, P. M., \& Gani, R. (2000). A multi-step and multi-level approach for computer aided molecular design. Computers \& Chemical Engineering, 24(2-7), 677-683

Harrison, R.G., Todd, P., Todd, P.W., Rudge, S.R., Petrides, D.P., 2015. Bioseparations Science and Engineering. Oxford University Press.

Heitzig, M., Gregson, C., Sin, G., \& Gani, R. (2011). Application of computer-aided multi-scale modelling framework - Aerosol case study. Computer Aided Chemical Engineering, 29, 16-20.

Holtbruegge, J., Kuhlmann, H. and Lutze, P., 2015. Process analysis and economic optimization of intensified process alternatives for simultaneous industrial scale production of dimethyl carbonate and propylene glycol. Chemical Engineering Research and Design, 93, pp.411-431.

Hong, W.H., Lee, S.Y., Hong, Y.K., Won, H.J., Huh, Y.S., Song, H., Lee, E.Z., 2009. Method for purifying succinic acid by crystallization of culture broth. WO2009/082050A1.

https://www.technavio.com/report/global-succinic-acid-market, Global succinic acid market 2017-2021, accessed on $12^{\text {th }}$ Oct, 2018.

ICIS chemicals indicative pricing, https:/www.icis.com/explore/chemicals/channel-info-chemicals-a-z/, accessesed in 2017

Industrial Price Comparison - Rocky Mountain Power, https://www.rockymountainpower.net/about/rar/ipc.html, accessed in 2018.

Inoue, T., Nagase, T., Hasegawa, Y., Kiyozumi, Y., Sato, K., Nishioka, M., ... Mizukami, F. (2007). Stoichiometric Ester Condensation Reaction Processes by Pervaporative Water Removal via Acid-Tolerant Zeolite Membranes. Industrial \& Engineering Chemistry Research, 46(11), 3743-3750.

Intratec utility pricing, https://www.intratec.us/chemical-markets/cooling-water-cost\#sub-table, accessed in 2017.

Isar, J., Agarwal, L., Saran, S., Kaushik, R. and Saxena, R.K., 2007. A statistical approach to study the interactive effects of process parameters on succinic acid production from Bacteroides fragilis. Anaerobe, 13(2), pp.50-56.

Jaksland, C.A., Gani, R. \& Lien, K.M., 1995. Separation process design and synthesis based on thermodynamic insights. Chemical Engineering Science, 50(3), pp.511-530.

Jantama, K., Haupt, M.J., Svoronos, S.A., Zhang, X., Moore, J.C., Shanmugam, K.T. and Ingram, L.O., 2008. Combining metabolic engineering and metabolic evolution to develop nonrecombinant strains of Escherichia coli C that produce succinate and malate. Biotechnology and bioengineering, 99(5), pp.1140-1153.

Kalakul, S., Malakul, P., Siemanond, K. and Gani, R., 2014. Integration of life cycle assessment software with tools for economic and sustainability analyses and process simulation for sustainable process design. Journal of cleaner production, 71, pp.98-109. 
Kim, Y. H., Park, L. K., Yiacoumi, S. and Tsouris, C., 2017. Modular chemical process intensification: a review. Annual review of chemical and biomolecular engineering, 8, pp.359-380.

King, C.J. and Poole, L.J., 1995. Carboxylic acid sorption regeneration process. U.S. Patent 5,412,126.

Kiss, A.A., Pragt, H. and van Strien, C., 2007. Overcoming equilibrium limitations in reactive dividing-wall columns. Computer Aided Chemical Engineering (Vol. 24, pp. 467-472).

Kuhn, J., Lakerveld, R., Kramer, H.J., Grievink, J. and Jansens, P.J., 2009. Characterization and dynamic optimization of membrane-assisted crystallization of adipic acid. Industrial \& Engineering Chemistry Research, 48(11), pp.5360-5369.

Lee, P., Lee, S., Hong, S. and Chang, H., 2002. Isolation and characterization of a new succinic acid-producing bacterium, Mannheimia succiniciproducens MBEL55E, from bovine rumen. Applied microbiology and biotechnology, 58(5), pp.663-668.

Lee, P.C., Lee, S., Hong, S.H., Chang, H.N. and Park, S.C., 2003. Biological conversion of wood hydrolysate to succinic acid by Anaerobiospirillum succiniciproducens. Biotechnology letters, 25(2), pp.111-114.

Lee, S.Y., Kim, J.M., Song, H., Lee, J.W., Kim, T.Y. and Jang, Y.S., 2008. From genome sequence to integrated bioprocess for succinic acid production by Mannheimia succiniciproducens. Applied microbiology and biotechnology, 79(1), pp.11-22.

Lee, S.Y., Lee, J.W., Choi, S. and Yi, J., Korea Advanced Institute of Science and Tech KAIST, 2014. Mutant microorganism producing succinic acid simultaneously using sucrose and glycerol, and method for preparing succinic acid using same. U.S. Patent 8,691,516B2.

Li, J., Demirel, S.E. and Hasan, M.F., 2017. Simultaneous process synthesis and process intensification using building blocks. Computer Aided Chemical Engineering (Vol. 40, pp. 1171-1176).

Li, Q., Siles, J.A. and Thompson, I.P., 2010. Succinic acid production from orange peel and wheat straw by batch fermentations of Fibrobacter succinogenes S85. Applied microbiology and biotechnology, 88(3), pp.671-678.

Litsanov, B., Brocker, M. and Bott, M., 2012. Towards homosuccinate fermentation: metabolic engineering of Corynebacterium glutamicum for anaerobic succinate production from glucose and formate. Applied and environmental microbiology, pp.AEM-07790.

Lutze, P., Babi, D. K., Woodley, J. M. \& Gani, R., 2013. Phenomena based methodology for process synthesis incorporating process intensification. Industrial \& Engineering Chemistry Research, 52(22), 7127-7144.

Lutze, P., Gani, R. \& Woodley, J. M., 2010. Process intensification: a perspective on process synthesis. Chemical Engineering and Processing: Process Intensification, 49(6), 547-558.

Madenoor Ramapriya, G., Tawarmalani, M. and Agrawal, R., 2014. Thermal coupling links to liquid-only transfer streams: A path for new dividing wall columns. AIChE Journal, 60(8), pp.2949-2961.

McKinlay, J.B., Vieille, C. and Zeikus, J.G., 2007. Prospects for a bio-based succinate industry. Applied microbiology and biotechnology, 76(4), pp.727-740.

Noorman, H. J., van Winden, W., Heijnen, J. J. and van der Lans, R. G. J. M., 2018. Intensified Fermentation Processes and Equipment. In Intensification of Biobased Processes, 16, pp.1-41. 
Okino, S., Inui, M. and Yukawa, H., 2005. Production of organic acids by Corynebacterium glutamicum under oxygen deprivation. Applied microbiology and biotechnology, 68(4), pp.475-480.

Papalexandri, K.P. and Pistikopoulos, E.N., 1996. Generalized modular representation framework for process synthesis. AIChE Journal, 42(4), pp.1010-1032.

Peschel, A., Jörke, A., Freund, H. and Sundmacher, K., 2012. Model-based development of optimal reaction concepts for plant wide process intensification. Computer Aided Chemical Engineering (Vol. 31, pp. 150-154).

Peters, M.S., K.D. Timmerhaus, R.E. West, Plant Design and Economics for Chemical Engineers, Mc Graw Hill, 2003.

Pirola, C., Galli, F., Manenti, F., Corbetta, M. and Bianchi, C.L., 2014. Simulation and related experimental validation of acetic acid/water distillation using p-xylene as entrainer. Industrial \& Engineering Chemistry Research, 53(46), pp.18063-18070.

Portha, J.F., Falk, L. and Commenge, J.M., 2014. Local and global process intensification. Chemical Engineering and Processing: Process Intensification, 84, pp.1-13.

PRO/II, https://sw.aveva.com/engineer-procure-construct/engineering-process-design/pro-ii (accessed 08 November, 2018).

Quaglia, A., Sarup, B., Sin, G. and Gani, R., 2013. Design of a generic and flexible data structure for efficient formulation of large scale network problems. In Computer Aided Chemical Engineering (Vol. 32, pp. 661-666). Elsevier.

Raab, A.M., Gebhardt, G., Bolotina, N., Weuster-Botz, D. and Lang, C., 2010. Metabolic engineering of Saccharomyces cerevisiae for the biotechnological production of succinic acid. Metabolic engineering, 12(6), pp.518-525.

Rong, B.G., Kolehmainen, E. and Turunen, I., 2008. Methodology of conceptual process synthesis for process intensification. Computer Aided Chemical Engineering (Vol. 25, pp. 283-288).

Rush, B.J. and Fosmer, A.M., BioAmber Inc, 2014. Methods for succinate production. U.S. Patent 0363862A1.

Sánchez, A.M., Bennett, G.N. and San, K.Y., 2005. Novel pathway engineering design of the anaerobic central metabolic pathway in Escherichia coli to increase succinate yield and productivity. Metabolic engineering, 7(3), pp.229-239.

Scholten, E. and Dägele, D., 2008. Succinic acid production by a newly isolated bacterium. Biotechnology letters, 30(12), pp.2143-2146.

Scholten, E., Renz, T. and Thomas, J., 2009. Continuous cultivation approach for fermentative succinic acid production from crude glycerol by Basfia succiniciproducens DD1. Biotechnology letters, 31(12), p.1947.

Schroder, H., Haefner, S., Von Abendroth, G., Hollmann, R., Raddatz, A., Ernst, H. and Gurski, H., BASF SE, 2014. Microbial succinic acid producers and purification of succinic acid. U.S. Patent 8,673,598.

Seifert, T., Sievers, S., Bramsiepe, C. and Schembecker, G., 2012. Small scale, modular and continuous: A new approach in plant design. Chemical Engineering and Processing: Process Intensification, 52, pp.140-150.

Siirola, J.J., 1996. Strategic process synthesis: Advances in the hierarchical approach. Computers \& chemical engineering, 20, pp.S1637-S1643.

Smith, K. B. \& Mackley, M. R., 2006. An experimental investigation into the scale-up of oscillatory flow mixing in baffled tubes. Chemical Engineering Research and Design, 84(11), 1001-1011. 
Song, H. and Lee, S.Y., 2006. Production of succinic acid by bacterial fermentation. Enzyme and microbial technology, 39(3), pp.352-361.

Soper, J.G., Schultz, M. and Binder, T.P., Archer Daniels Midland Co, 2013. Purification of succinic acid. WO2013/169447A1.

Tan, J.P., Jahim, J.M., Harun, S. and Wu, T.Y., 2017. Overview of the Potential of Bio-Succinic Acid Production from Oil Palm Fronds. Journal of Physical Science, 28.

Tian, Y., Demirel, S.E., Hasan, M.F. and Pistikopoulos, E.N., 2018. An Overview of Process Systems Engineering Approaches for Process Intensification: State of the Art. Chemical Engineering and Processing-Process Intensification.

Tula, A. K., Eden, M. R., \& Gani, R., 2015. Process synthesis, design and analysis using a process-group contribution method. Computers \& Chemical Engineering, 81, 245-259.

Tula, A.K., Babi, D.K., Bottlaender, J., Eden, M.R. and Gani, R., 2017. A computer-aided software-tool for sustainable process synthesis-intensification. Computers \& Chemical Engineering, 105, pp.74-95.

Välimäki C., Towards sustainable future, accessed on 10 October, 2018, https://www.sustainablebrands.com/news _and_views/chemistry_materials_packaging/christina_v\%C3\%A4lim\%C3\%A4ki/why_sustainability_future_che mical

Van Baelen, D., Van der Bruggen, B., Van den Dungen, K., Degrève, J. and Vandecasteele, C., 2005. Pervaporation of water-alcohol mixtures and acetic acid-water mixtures. Chemical Engineering Science, 60(6), pp.1583-1590.

Van De Graaf, M.J., Vallianpoer, F., Fiey, G., Delattre, L. and Schulten, E.A.M., Roquette Freres and DSM IP Assets BV, 2012. Process for the crystallization of succinic acid. U.S. Patent 2012/0238722A1.

Van Gerven, T. \& Stankiewicz, A., 2009. Structure, energy, synergy, time: The fundamentals of process intensification. Industrial \& engineering chemistry research, 48(5), 2465-2474.

Vaswani, S., 2010. Bio-based succinic acid. California: Sri Consulting. Review, (14).

Vemuri, G.N., Eiteman, M.A. and Altman, E., 2002. Effects of growth mode and pyruvate carboxylase on succinic acid production by metabolically engineered strains of Escherichia coli. Applied and Environmental Microbiology, 68(4), pp.1715-1727.

Vogel, H.C. and Todaro, C.M., 1996. Fermentation and biochemical engineering handbook: principles, process design and equipment. William Andrew.

Wang, C., Ming, W., Yan, D., Zhang, C., Yang, M., Liu, Y., Zhang, Y., Guo, B., Wan, Y. and Xing, J., 2014. Novel membrane-based biotechnological alternative process for succinic acid production and chemical synthesis of biobased poly (butylene succinate). Bioresource technology, 156, pp.6-13.

Ycharts indicative pricing, https://ycharts.com/indicators/us_sugar_futures_contract_price, Accessed in 2017.

Yedur, S., Berglund, K.A. and Dunuwila, D.D., Applied Carbochemicals and Michigan State University, 2001. Succinic acid production and purification. U.S. Patent 6,265,190.

Yuzbashev, T.V., Yuzbasheva, E.Y., Sobolevskaya, T.I., Laptev, I.A., Vybornaya, T.V., Larina, A.S., Matsui, K., Fukui, K. and Sineoky, S.P., 2010. Production of succinic acid at low pH by a recombinant strain of the aerobic yeast Yarrowia lipolytica. Biotechnology and bioengineering, 107(4), pp.673-682. 


\section{Sustainable solutions by integrating process synthesis-intensification}

Nipun Garg ${ }^{\mathrm{a}}$, John M. Woodley ${ }^{\mathrm{a}}$, Rafiqul Gani ${ }^{\mathrm{b}}$, Georgios M. Kontogeorgis ${ }^{\mathrm{a}}$

${ }^{a}$ Department of Chemical and Biochemical Engineering, Technical University of Denmark, Søltofts Plads, DK-2800 Kgs. Lyngby, Denmark

${ }^{b}$ PSE for SPEED, Skyttemosen 6, DK-3450 Allerod, Denmark

*Corresponding author: Georgios M. Kontogeorgis, Ph. +45 4525 28 59, email: gk@ kt.dtu.dk,

Keywords: Process Synthesis; Process Intensification; Phenomena-based methodology; Systematic framework; Sustainable solutions 
S1 Raw material, product and utility price data for bio-succinic acid case study

Table S1.1: Price of the raw material and product $\$ / \mathrm{kg}$ (Stage 1)

\begin{tabular}{lcc}
\hline Compound & $\begin{array}{c}\text { Price } \\
\text { (Scenario 1 and 2) }\end{array}$ & $\begin{array}{c}\text { Price } \\
\text { (Scenario 3) }\end{array}$ \\
\hline Glucose (GLU) & 0.428 & 0.270 \\
Glycerol (GLY) & 0.925 & 0.230 \\
Sucrose (SUC) & 0.485 & 0.265 \\
Maltose (MAL) & 0.485 & 0.265 \\
Succinic acid (SUCA) & 2.860 & 2.860 \\
\hline
\end{tabular}

Table S1.2: Price of the utilities in the bio succinic-acid superstructure network (Stage 1)

\begin{tabular}{lcc}
\hline Utility & $\begin{array}{c}\text { Price } \\
(\text { Scenario 1 and 2) }\end{array}$ & $\begin{array}{c}\text { Price } \\
(\text { Scenario 3) }\end{array}$ \\
\hline LP Steam $(\$ / \mathrm{t})$ & 27.000 & 5.000 \\
Cooling water $\left(\$ / \mathrm{m}^{3}\right)$ & 0.057 & 0.490 \\
Electricity $(\$ / \mathrm{kWh})$ & 0.120 & 0.080 \\
\hline
\end{tabular}




\section{S2 List of databases and algorithms used in Phenomena based synthesis methodology}

Table S2.1: List of databases

\begin{tabular}{llll}
\hline Database & Description & $\begin{array}{c}\text { Stage/Step } \\
\text { (From framework) }\end{array}$ & $\begin{array}{c}\text { Reference } \\
\text { table }\end{array}$ \\
\hline $\begin{array}{l}\text { Phenomena Building Blocks } \\
\text { (PBB's) }\end{array}$ & $\begin{array}{l}\text { A list of phenomena building blocks including } \\
\text { different classes }\end{array}$ & Stage-3/Step - 6 & S2.3 \\
$\begin{array}{l}\text { Translation of Unit-ops to } \\
\text { tasks and PBB's }\end{array}$ & $\begin{array}{l}\text { A list of different unit-ops translated to tasks and to } \\
\text { PBB's required, translating base case flowsheet to } \\
\text { task and phenomena based flowsheet. }\end{array}$ & Stage-3/Step - 6 & S2.4 \\
$\begin{array}{l}\text { Process hotspots to desirable } \\
\text { tasks and PBB's }\end{array}$ & $\begin{array}{l}\text { A list of alternative tasks and phenomena building } \\
\text { blocks (PBB's) based on process hotspots }\end{array}$ & Stage-3/Step - 6 & S2.5 \\
$\begin{array}{l}\text { Database for basic structures } \\
\text { A list of basic structures that performs a task or set } \\
\text { of tasks. }\end{array}$ & Stage-3/Step - 7 & S2.6 \\
$\begin{array}{l}\text { Translation of basic structures } \\
\text { to unit-ops }\end{array}$ & $\begin{array}{l}\text { It consists of database guidance to translate basic } \\
\text { structures to unit ops. }\end{array}$ & Stage-3/Step - 7 & S2.7 \\
\hline
\end{tabular}

Table S2.2: List of algorithms (extended application)

\begin{tabular}{|c|c|c|c|}
\hline Algorithm & Step (Stage-3) & Objective & Reference \\
\hline 1 & 6 & Transform the base case flowsheet to a task-based flowsheet & \\
\hline 2 & 6 & $\begin{array}{l}\text { Identify PBBs in the base case flowsheet and transform a task-based } \\
\text { base case flowsheet, to a phenomena-based flowsheet }\end{array}$ & \\
\hline 3 & 6 & $\begin{array}{l}\text { Identify desirable task and PBBs for addressing the identified } \\
\text { process hotspots. Identify final list of PBB (PBB search space) }\end{array}$ & \\
\hline 4 & 7 & $\begin{array}{l}\text { Generate feasible simultaneous phenomena building blocks (SPBs) } \\
\text { using combination rules }\end{array}$ & \\
\hline 5 & 7 & $\begin{array}{l}\text { Generate a task-based superstructure for identification of task based } \\
\text { flowsheets (sequential step) }\end{array}$ & Babi et al., 2015 \\
\hline 6 & 7 & Identify tasks to be performed & \\
\hline 7 & 7 & $\begin{array}{l}\text { Generate basic structures from the combination of SPBs using } \\
\text { combination rules }\end{array}$ & \\
\hline 8 & 7 & $\begin{array}{l}\text { Generation of task-based flowsheets based on the identification of } \\
\text { basic structures that perform a task }\end{array}$ & \\
\hline 9 & 7 & $\begin{array}{l}\text { Translation of basic structures into unit operations which constitute } \\
\text { the final flowsheet alternatives }\end{array}$ & \\
\hline
\end{tabular}

Table S2.3: Phenomena Building Blocks (PBB's) database (see section 2.1 in article for abbreviations), ${ }^{\text {x }} \mathrm{PVL}$ - special class of phenomena denoting membrane pervaporation

\begin{tabular}{c|lllllllll}
\hline Phenomena/Class & $\mathbf{M}$ & $\mathbf{2} \mathbf{p h M}$ & $\mathbf{R}$ & $\mathbf{P C}$ & $\mathbf{C}$ & $\mathbf{H}$ & $\mathbf{P T}$ & $\mathbf{P S}$ & $\mathbf{D}$ \\
\hline $\mathbf{V}$ & $*$ & - & $*$ & - & - & - & - & - & - \\
$\mathbf{L}$ & $*$ & - & $*$ & - & - & - & - & - & - \\
$\mathbf{S}$ & $*$ & - & $*$ & - & - & - & - & - & - \\
$\mathbf{V V}$ & - & - & - & - & - & - & $*$ & $*$ & - \\
$\mathbf{L L}$ & - & $*$ & - & $*$ & - & - & $*$ & $*$ & - \\
$\mathbf{S S}$ & - & - & - & $*$ & - & - & - & $*$ & - \\
$\mathbf{V L}$ & $*$ & $*$ & $*$ & $*$ & - & - & $*$ & $*$ & - \\
$\mathbf{L S}$ & $*$ & $*$ & $*$ & $*$ & - & - & $*$ & $*$ & - \\
$\mathbf{V S}$ & $*$ & $*$ & $*$ & $*$ & - & - & $*$ & $*$ & - \\
$\mathbf{P V L}$ & - & - & - & - & - & - & $*$ & - & - \\
\hline
\end{tabular}


Table S2.4: Database for identification of tasks and phenomena building blocks based on unit operations (extended excerpt)

\begin{tabular}{|c|c|c|c|c|c|c|c|}
\hline Operation & $\begin{array}{l}\text { Feed } \\
\text { phase }\end{array}$ & Task & Principle PBB & PBB's & $\begin{array}{c}\text { Created/added } \\
\text { phase }\end{array}$ & MSA-Y/N & Agent(s) \\
\hline Batch reactor & $\begin{array}{c}\text { S, V } \\
\text { and/or L }\end{array}$ & Reaction & $\mathrm{R}$ & $\mathrm{R}, \mathrm{C}$ (exothermic), H (endothermic) & - & $\mathrm{Y} / \mathrm{N}$ & $\begin{array}{l}\text { Liquid solvent } \\
\text { (MSA) and } \\
\text { energy transfer } \\
\text { (ESA) }\end{array}$ \\
\hline CSTR & $\mathrm{L}$ & Reaction & $\mathrm{R}$ & $\mathrm{R}, \mathrm{C}$ (exothermic), H (endothermic) & - & $\mathrm{Y} / \mathrm{N}$ & $\begin{array}{l}\text { Liquid solvent } \\
\text { (MSA) and } \\
\text { energy transfer } \\
\text { (ESA) }\end{array}$ \\
\hline Distillation & $\begin{array}{l}\mathrm{V} \text { and/or } \\
\mathrm{L}\end{array}$ & Separation & $\mathrm{PT}(\mathrm{VL})$ & PC(VL), PT(VL), PS(VL), C, H & $\begin{array}{l}\text { Vapor and } \\
\text { liquid }\end{array}$ & $\mathrm{N}$ & $\begin{array}{l}\text { Heat transfer } \\
\text { (ESA) and } \\
\text { sometimes } \\
\text { work transfer }\end{array}$ \\
\hline $\begin{array}{l}\text { Dividing Wall } \\
\text { Column }\end{array}$ & $\begin{array}{l}\mathrm{V} \text { and/or } \\
\mathrm{L}\end{array}$ & Separation & $\mathrm{PT}(\mathrm{VL})$ & $\mathrm{PC}(\mathrm{VL}), \mathrm{PT}(\mathrm{VL}), \mathrm{PS}(\mathrm{VL}), \mathrm{C}, \mathrm{H}$ & $\begin{array}{l}\text { Vapor and } \\
\text { liquid }\end{array}$ & $\mathrm{N}$ & $\begin{array}{l}\text { Heat transfer } \\
\text { (ESA) and } \\
\text { sometimes } \\
\text { work transfer }\end{array}$ \\
\hline \multirow{2}{*}{ Crystallization } & $\mathrm{L}$ & Separation & PT(LS) & $\begin{array}{c}\text { PC(LS), PT(LS), PS(LS), H, PT(VL), } \\
\text { PS(VL) }\end{array}$ & $\begin{array}{l}\text { Solid (and } \\
\text { vapor) }\end{array}$ & $\mathrm{N}$ & $\begin{array}{l}\text { Energy transfer } \\
\text { (ESA) }\end{array}$ \\
\hline & $\mathrm{L}$ & Separation & $\mathrm{PT}(\mathrm{LS})$ & PC(LS), PT(LS), PS(LS), C & Solid & $\mathrm{N}$ & $\begin{array}{l}\text { Energy transfer } \\
\quad \text { (ESA) }\end{array}$ \\
\hline $\begin{array}{l}\text { Membrane- } \\
\text { Pervaporation }\end{array}$ & $\mathrm{V}$ & Separation & PT(PVL) & PC(VL), PT(PVL), PS(VL), C & Liquid & $\mathrm{N}$ & $\begin{array}{l}\text { Energy transfer } \\
\quad \text { (ESA) }\end{array}$ \\
\hline $\begin{array}{l}\text { Reactive } \\
\text { Distillation }\end{array}$ & $\begin{array}{l}\mathrm{V} \text { and/or } \\
\mathrm{L}\end{array}$ & $\begin{array}{l}\text { Reaction + } \\
\text { Separation }\end{array}$ & $\mathrm{R}, \mathrm{PT}(\mathrm{VL})$ & R, PC(VL), PT(VL), PS(VL), C, H & $\begin{array}{l}\text { Vapor and } \\
\text { liquid }\end{array}$ & $\mathrm{N}$ & $\begin{array}{l}\text { Energy transfer } \\
\quad \text { (ESA) }\end{array}$ \\
\hline Membrane reactor & $\begin{array}{l}\mathrm{L} \text { and/or } \\
\mathrm{V}\end{array}$ & $\begin{array}{l}\text { Reaction }+ \\
\text { Separation }\end{array}$ & R, PT(PVL/VV) & R, PC(VL), PT(PVL/VV), PS(VL/VV) & - & $\mathrm{N}$ & $\begin{array}{l}\text { Energy transfer } \\
\quad \text { (ESA) }\end{array}$ \\
\hline $\begin{array}{l}\text { Membrane } \\
\text { distillation }\end{array}$ & $\begin{array}{l}\text { V and/or } \\
\text { L }\end{array}$ & Separation & $\begin{array}{c}\text { PT(VL), } \\
\text { PT(PVL/VV/LL) }\end{array}$ & $\begin{array}{c}\mathrm{PC}(\mathrm{VL}), \mathrm{PT}(\mathrm{VL}), \mathrm{PS}(\mathrm{VL}), \mathrm{PT}(\mathrm{PVL} / \mathrm{VV}), \\
\mathrm{PS}(\mathrm{VV})(\text { for VP), C, H }\end{array}$ & $\mathrm{V}$ and $\mathrm{L}$ & $\mathrm{N}$ & $\begin{array}{l}\text { Energy transfer } \\
\text { (ESA) }\end{array}$ \\
\hline Filtration & $\mathrm{L}$ and/or $\mathrm{S}$ & Separation & $\mathrm{PC}(\mathrm{LS})$ & PC(LS), PS(LS) & - & $\mathrm{N}$ & - \\
\hline $\begin{array}{l}\text { Membrane- } \\
\text { Separation } \\
\text { (eg Reverse or } \\
\text { forward osmossis) }\end{array}$ & $\mathrm{L}$ & Separation & PS(LL) & $\mathrm{PC}(\mathrm{LL}), \mathrm{PS}(\mathrm{LL})$ & - & $\mathrm{N}$ & - \\
\hline $\begin{array}{l}\text { Membrane-reactive } \\
\text { distillation }\end{array}$ & $\begin{array}{l}\mathrm{V} \text { and/or } \\
\mathrm{L}\end{array}$ & $\begin{array}{l}\text { Reaction }+ \\
\text { Separation }\end{array}$ & $\begin{array}{l}\text { R, PT(VL), } \\
\text { PT(PVL/VV) }\end{array}$ & $\begin{array}{c}\mathrm{R}, \mathrm{PC}(\mathrm{VL}), \mathrm{PT}(\mathrm{VL}), \mathrm{PS}(\mathrm{VL}), \mathrm{PT}(\mathrm{PVL} / \mathrm{VV}), \\
\mathrm{PS}(\mathrm{VV})(\text { for VP), C, H }\end{array}$ & $\mathrm{V}$ and $\mathrm{L}$ & $\mathrm{N}$ & $\begin{array}{l}\text { Energy transfer } \\
\text { (ESA) }\end{array}$ \\
\hline
\end{tabular}


Table S2.5: Database for translation of process hotspots to identify desirable task and phenomena (extended excerpt)

\begin{tabular}{|c|c|c|c|c|c|c|}
\hline Process-Hotspot & Main Task & Property/Binary Ratio & $\begin{array}{l}\text { Alternative } \\
\text { Task }\end{array}$ & $\begin{array}{l}\text { Mass Separating } \\
\text { agent? }\end{array}$ & $\begin{array}{l}\text { Additional } \\
\text { information }\end{array}$ & PBB \\
\hline Activation problems & Reaction & Calculate $\Delta$ Grxn & Reaction & $\mathrm{N}$ & Use of catalyst & $\mathrm{M}, \mathrm{H}$ \\
\hline \multirow[t]{3}{*}{ Limiting equilibrium } & Reaction & Solubility parameter & Separation & $\mathrm{Y}$ & Equilibrium shift & $\begin{array}{l}\text { PC(LL), } \\
\text { PT(LL), } \\
\text { PS(LL) }\end{array}$ \\
\hline & & $\begin{array}{l}\text { Vapor pressure, heat of vaporization, } \\
\text { boiling point }\end{array}$ & Separation & $\mathrm{N}$ & Equilibrium shift & $\begin{array}{l}\text { PC(VL), } \\
\text { PT(VL), } \\
\text { PS(VL) }\end{array}$ \\
\hline & & $\begin{array}{l}\text { Molar volume, solubility parameter, } \\
\text { molar volume, radius of gyration, } \\
\text { dipole moment }\end{array}$ & Separation & $\mathrm{N}$ & Equilibrium shift & $\begin{array}{l}\text { PT(PVL), } \\
\text { PT(VV), } \\
\text { PS(VV) }\end{array}$ \\
\hline Highly exothermic & Reaction & Calculate $\Delta$ Hrxn & Reaction & $\mathrm{N}$ & Cooling & $\mathrm{C}$ \\
\hline Formation of undesired side-products & Reaction & & Reaction & $\mathrm{N}$ & $\begin{array}{l}\text { Reaction for reacting } \\
\text { away side products }\end{array}$ & $\mathrm{R}$ \\
\hline \multirow[t]{3}{*}{ Formation of undesired side-products } & Reaction & Solubility parameter & Separation & $\mathrm{Y}$ & $\begin{array}{l}\text { Separation of side- } \\
\text { products }\end{array}$ & $\begin{array}{l}\text { PC(LL), } \\
\text { PT(LL), } \\
\text { PS(LL) }\end{array}$ \\
\hline & & $\begin{array}{l}\text { Vapor pressure, heat of vaporization, } \\
\text { boiling point }\end{array}$ & Separation & $\mathrm{N}$ & $\begin{array}{l}\text { Separation of side- } \\
\text { products }\end{array}$ & $\begin{array}{l}\text { PC(VL), } \\
\text { PT(VL), } \\
\text { PS(VL) }\end{array}$ \\
\hline & & $\begin{array}{l}\text { Molar volume, solubility parameter, } \\
\text { molar volume, radius of gyration, } \\
\text { dipole moment }\end{array}$ & Separation & $\mathrm{N}$ & $\begin{array}{l}\text { Separation of side- } \\
\text { products }\end{array}$ & $\begin{array}{l}\text { PT(PVL), } \\
\text { PT(VV), } \\
\text { PS(VV) }\end{array}$ \\
\hline $\begin{array}{l}\text { Contact problems of raw materials/limited } \\
\text { mass transfer }\end{array}$ & Reaction & & Mixing & $\mathrm{N}$ & Mixing alternatives & $\mathrm{M}, 2 \mathrm{phM}$ \\
\hline Explosive mixture & Reaction & Mixture flash point & Reaction & & Cooling & $\mathrm{C}$ \\
\hline Degradation by temperature & Reaction & & Reaction & $\mathrm{N}$ & Cooling & $\mathrm{C}$ \\
\hline Azeotrope & Separation & $\begin{array}{l}\text { Molar volume, solubility parameter, } \\
\text { Van der Waal volume, radius of } \\
\text { gyration, dipole moment }\end{array}$ & Separation & $\mathrm{N}$ & $\begin{array}{l}\text { Formation of } \\
\text { Azeotrope(s) }\end{array}$ & $\begin{array}{l}\text { PT(PVL), } \\
\text { PT(VV), } \\
\text { PS(VV) }\end{array}$ \\
\hline Insufficient purity & Separation & Solubility parameter, melting point & Separation & $\mathrm{N}$ & DF analysis & $\begin{array}{l}\text { PT(LS), } \\
\text { PS(LS) }\end{array}$ \\
\hline High energy consumption/demand & Separation & $\begin{array}{l}\text { Solubility parameter, Molecular } \\
\text { weight, molar volume }\end{array}$ & Separation & $\mathrm{Y}$ & DF analysis & $\begin{array}{l}\text { PC(LL), } \\
\text { PS(LL) }\end{array}$ \\
\hline
\end{tabular}


Table S2.6: Basic structures database (extended excerpt)

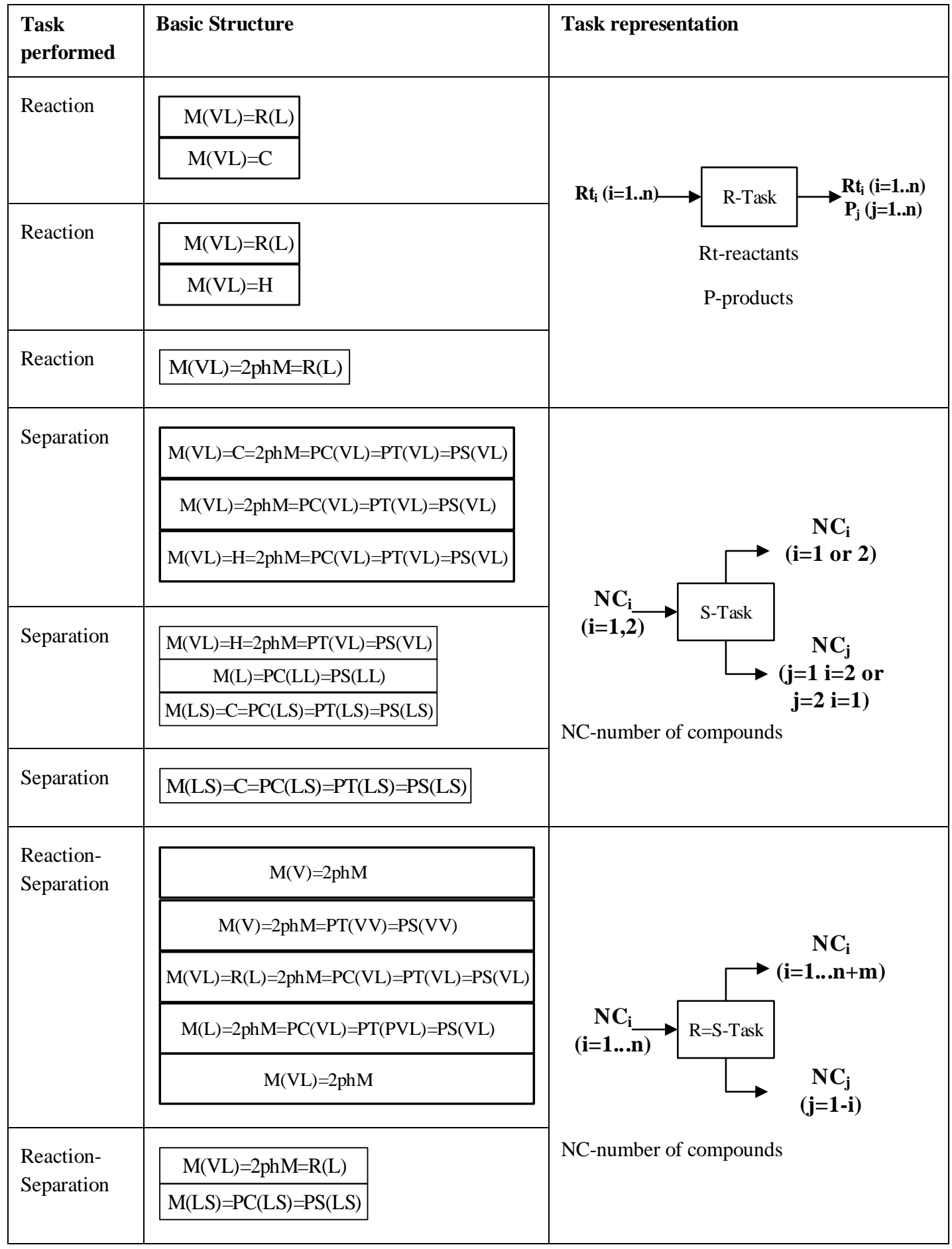


Table S2.7: Database for translation of basic structures to unit operations (extended excerpt)

\begin{tabular}{|c|c|c|c|c|c|}
\hline SPB building block in Basic Structure & Task & $\begin{array}{l}\text { Reaction/Separation } \\
\text { Operation }\end{array}$ & Screening 1: Feed phase & $\begin{array}{l}\text { Screening 2: } \\
\text { MSA-Y/N }\end{array}$ & $\begin{array}{l}\text { Screening 3: } \\
\text { Azeotrope }\end{array}$ \\
\hline$=\mathrm{M}=\mathrm{R}=$ & Reaction & Batch reactor & $\begin{array}{l}\text { Solid, gas (vapor) and/or } \\
\text { liquid }\end{array}$ & $\mathrm{Y} / \mathrm{N}$ & $\mathrm{N}$ \\
\hline$=2 \mathrm{phM}=\mathrm{PC}(\mathrm{VL})=\mathrm{PT}(\mathrm{VL})=\mathrm{PS}(\mathrm{VL})$ & Separation & $\begin{array}{l}\text { Partial condensation or } \\
\text { vaporization }\end{array}$ & Vapor and/or liquid & $\mathrm{N}$ & $\mathrm{N}$ \\
\hline$=2 \mathrm{phM}=\mathrm{PC}(\mathrm{VL})=\mathrm{PT}(\mathrm{VL})=\mathrm{PS}(\mathrm{VL})$ & Separation & Flash vaporization & Liquid & $\mathrm{N}$ & $\mathrm{N}$ \\
\hline$=2 \mathrm{phM}=\mathrm{PC}(\mathrm{VL})=\mathrm{PT}(\mathrm{VL})=\mathrm{PS}(\mathrm{VL})$ & Separation & Distillation & Vapor and/or liquid & $\mathrm{N}$ & $\mathrm{Y} / \mathrm{N}$ \\
\hline$=2 \mathrm{phM}=\mathrm{PC}(\mathrm{LL})=\mathrm{PT}(\mathrm{LL})=\mathrm{PS}(\mathrm{LL})$ & Separation & $\begin{array}{l}\text { Liquid-liquid extraction (two } \\
\text { solvent) }\end{array}$ & Liquid & $\mathrm{Y}$ & $\mathrm{Y}$ \\
\hline$=\mathrm{PC}(\mathrm{LS})=\mathrm{PS}(\mathrm{LS})$ & Separation & Drying & Liquid/solid & $\mathrm{Y}$ & $\mathrm{N}$ \\
\hline$=2 \mathrm{phM}=\mathrm{PC}(\mathrm{VL})=\mathrm{PT}(\mathrm{VL})=\mathrm{PS}(\mathrm{VL})$ & Separation & Evaporation & Liquid & $\mathrm{N}$ & $\mathrm{N}$ \\
\hline$=2 \mathrm{phM}=\mathrm{PC}(\mathrm{VL})=\mathrm{PT}(\mathrm{VL})=\mathrm{PS}(\mathrm{VL})$ & Separation & Dividing Wall Column & Vapor and/or liquid & $\mathrm{N}$ & $\mathrm{N}$ \\
\hline$=2 \mathrm{phM}=\mathrm{PC}(\mathrm{LL})=\mathrm{PS}(\mathrm{LL})$ & Separation & Decanter & Liquid & $\mathrm{N}$ & $\mathrm{Y} / \mathrm{N}$ \\
\hline$=\mathrm{PT}(\mathrm{LS})=\mathrm{PS}(\mathrm{LS}), \mathrm{PT}(\mathrm{MLL})=\mathrm{PS}(\mathrm{LL}), \mathrm{ES}(\mathrm{H} / \mathrm{C})$ & Separation & Membrane crystallization & Liquid & $\mathrm{N}$ & $\mathrm{N}$ \\
\hline$=\mathrm{PC}(\mathrm{VL})=\mathrm{PT}(\mathrm{VV})=\mathrm{PS}(\mathrm{VV})$ & Separation & Membrane-Vapor-permeation & Vapor & $\mathrm{N}$ & $\mathrm{Y}$ \\
\hline$=\mathrm{R}=\mathrm{PC}(\mathrm{VL})=\mathrm{PT}(\mathrm{PVL})=\mathrm{PS}(\mathrm{VL})$ & Reaction +Separation & $\begin{array}{l}\text { Membrane (Pervaporation) } \\
\text { Reactor }\end{array}$ & Vapor and/or Liquid & $\mathrm{N}$ & $\mathrm{Y}$ \\
\hline$=\mathrm{R}=\mathrm{PC}(\mathrm{LS})=\mathrm{PS}(\mathrm{LS})$ & Reaction+ Separation & Membrane Reactor (bio) & Liquid and/or solid & $\mathrm{N}$ & $\mathrm{Y} / \mathrm{N}$ \\
\hline$=\mathrm{R}=\mathrm{PC}(\mathrm{VL})=\mathrm{PT}(\mathrm{VL})=\mathrm{PS}(\mathrm{VL})$ & Reaction +Separation & Reactive Distillation & Vapor and/or Liquid & $\mathrm{N}$ & $\mathrm{Y} / \mathrm{N}$ \\
\hline$=\mathrm{R}=\mathrm{PC}(\mathrm{VL})=\mathrm{PT}(\mathrm{PVL})=\mathrm{PS}(\mathrm{VL}), \mathrm{PT}(\mathrm{VL})$ & Reaction +Separation & Membrane reactive distillation & Vapor and/or Liquid & $\mathrm{N}$ & $\mathrm{Y} / \mathrm{N}$ \\
\hline
\end{tabular}


S3 List of tools used at different stages in the framework

\begin{tabular}{|c|c|c|c|c|c|c|c|c|}
\hline Tool & $\begin{array}{c}\text { ICAS } \\
\text { database }\end{array}$ & ProPred & Super-O & $\begin{array}{l}\text { ASPEN } \\
\text { / PROII }\end{array}$ & ECON & SuatainPro & LCSoft & MoT \\
\hline $\begin{array}{l}\text { Stage-I } \\
\text { (Synthesis) }\end{array}$ & $*$ & $*$ & $*$ & & & & & \\
\hline $\begin{array}{l}\text { Stage-II } \\
\text { (Design and analysis) }\end{array}$ & & & & $*$ & $*$ & $*$ & $*$ & $*$ \\
\hline $\begin{array}{l}\text { Stage-II } \\
\text { (Innovation - Phenomena based intensification) }\end{array}$ & $*$ & $*$ & & $*$ & $*$ & $*$ & $*$ & $*$ \\
\hline
\end{tabular}

\section{References}

Babi, D. K., Holtbruegge, J., Lutze, P., Górak, A., Woodley, J. M. \& Gani, R., 2015. Sustainable process synthesis-intensification. Computers \& Chemical Engineering, 81, 218-244. 